\title{
Turmalinitos Vulcanogênicos da Formação Morro da Pedra Preta do Grupo Serra do Itaberaba (SP): Petrografia, Composição Química da Turmalina e Implicações Metalogenéticas
}

\author{
Paulo Beljavskis' (beljavskis@terra.com.br), Gianna Maria Garda', Marcos de Souza Mansueto², Dailto Silva ${ }^{3}$ \\ 'Departamento de Geologia Sedimentar e Ambiental - Instituto de Geociências - USP \\ R. do Lago 562, CEP 05508-080, São Paulo, SP, BRA \\ ${ }^{2}$ Departamento de Mineralogia e Geotectônica - Instituto de Geociências - USP, São Paulo, SP, BRA \\ ${ }^{3}$ Instituto de Geociências - UNICAMP, Campinas, SP, BRA
}

Recebido em 10 de outubro de 2003; aceito em 24 de novembro de 2004

Palavras-chave: Grupo Serra do Itaberaba, Formação Morro da Pedra Preta, turmalinitos, atividade vulcano-exalativa de fundo oceânico.

\section{RESUMO}

Turmalinitos associados a anfibolitos, metachert, formação ferrífera, metatufos, rochas metassedimentares, metavulcanoclásticas e calciossilicáticas são encontrados na Formação Morro da Pedra Preta, seqüência metavulcano-sedimentar basal do Grupo Serra do Itaberaba (SP - Brasil). A deformação da rocha, que é formada por leitos ricos em turmalina alternados com leitos ricos em quartzo, a presença de clastos do tipo rip-up e a química de rocha total semelhante à das rochas metassedimentares comprovam a origem sin-sedimentar dos turmalinitos. Análises químicas da turmalina por microssonda eletrônica mostram que, para a turmalina dos turmalinitos associados a metatufos, formação ferrífera, metachert e rochas metavulcanoclásticas e metassedimentares, as composições são intermediárias à série schorlita-dravita, enquanto para os turmalinitos associados a anfibolitos, metatufos e a rochas calciossilicáticas, as composições são intermediárias à série dravita-uvita. As primeiras apresentam conteúdos baixos de $\mathrm{Ca}$ e elevados de $\mathrm{Al}$ e $\mathrm{Na}$, com variações nos teores de $\mathrm{Fe}$ e $\mathrm{Mg}$ (série schorlita-dravita), e as últimas são caracterizadas por teores baixos de $\mathrm{Na}$ e $\mathrm{Al}$ e altos de $\mathrm{Mg}$ e $\mathrm{Ca}$, contendo adicionalmente flúor. A componente schorlita da turmalina dos turmalinitos situados em porções proximais aos centros de atividade vulcano-exalativa de fundo oceânico é indicativa do potencial para ouro da Formação Morro da Pedra, o que contrasta com as condições requeridas para a formação de depósitos de sulfetos maciços (fluidos hipersalinos e associação com turmalinitos magnesianos). A turmalina dos vários turmalinitos da Formação Morro da Pedra Preta não é tipicamente magnesiana e sua composição foi mais fortemente influenciada pela composição das rochas circundantes do que por aquela dos fluidos hidrotermais, especialmente no caso em que o turmalinito se depositou em uma posição intermediária a distal em relação ao centro de atividade vulcano-exalativa.

Keywords: Serra do Itaberaba Group, Morro da Pedra Preta Formation, tourmalinites, seafloor volcano-exhalative activity.

\section{ABSTRACT}

Tourmalinites associated with amphibolites, metachert, iron formation, metatuffs, metasedimentary, metavolcaniclastic and calc-silicate rocks were found in the Morro da Pedra Preta Formation, basal metavolcano-sedimentary sequence of the Serra do Itaberaba Group (São Paulo State, Brazil). The syn-sedimentary origin of the tourmalinites is attested by the deformation of the alternating tourmaline-rich and quartz-rich layers, the presence of rip-up clasts, and whole-rock chemistry similar to that of surrounding metassedimentary rocks. Microprobe analyses show that the tourmaline compositions are: 1) within the schorl-dravite series, for the examples associated with metatuffs, iron formation, metachert metavolcaniclastic and metasedimentary rocks, and 2) within the dravite-uvite series, for those associated with amphibolites, metatuffs and calcsilicate rocks. The former are characterized by low $\mathrm{Ca}$ and high $\mathrm{Na}$ and $\mathrm{Al}$ contents, with variable $\mathrm{Fe}$ and $\mathrm{Mg}$ contents (schorldravite series), whereas the latter, a F-bearing tourmaline, has low $\mathrm{Na}$ and $\mathrm{Al}$ and high $\mathrm{Mg}$ and $\mathrm{Ca}$ contents. The schorl 
component of the tourmaline of the proximal tourmalinites is indicative of the potential of Morro da Pedra Preta Formation for gold, which contrasts with the conditions required for the formation of volcanic massive sulphide deposits (hypersaline fluids and association with magnesian tourmalinites). The tourmaline of the various tourmalinites of the Morro da Pedra Preta Formation is not typically magnesian and its composition was more strongly influenced by the composition of the neighboring rocks than that of the hydrothermal fluids, especially when the tourmalinite was deposited in an intermediate to distal position in relation to the volcano-exhalative center.

\section{INTRODUÇÃO}

Segundo Slack (1982), o turmalinito é uma rocha estratiforme-stratabound, constituída em volume por mais de $15-20 \%$ de turmalina. Sua ocorrência é comum em terrenos vulcano-sedimentares neo- a mesoproterozóicos metamorfizados (Slack et al., 1984; Plimer, 1988; King, 2000).

A formação dos turmalinitos é, na maioria das vezes, atribuída ao metassomatismo e à ação de fluidos pneumatolítico-hidrotermais derivados de intrusões de rochas ácidas. Slack et al. (1984) afirmam que processos vulcanogênicos exalativos, geradores de evaporitos e diagenéticos podem também originar turmalinitos, em particular aqueles em que se reconhecem estruturas sedimentares e que não se associam a rochas graníticas e pegmatíticas. Turmalinitos dessa natureza foram descritos em Passagem de Mariana (Quadrilátero Ferrífero - Fleischer e Routier, 1973), em Broken Hill (Austrália - Slack et al., 1984), em Golden Dyke Dome (Austrália - Plimer, 1986), em Rum Jungle (Austrália - Boné, 1988), no cinturão móvel de Namaqua Central (África do Sul - Willner, 1992), no cinturão de Isua (Groenlândia - Appel, 1995), em Bin Yauri (Nigéria - Garba, 1996), em Sullivan (British Columbia - Jiang et al., 1998) e no Grupo Serra do Itaberaba (Brasil - Juliani, 1993; Beljavskis, 2003).

Plimer (1988) considera que a ocorrência de turmalinitos é indicativa da existência de atividades exalativas vulcanogênicas, às quais podem associar-se depósitos de sulfetos maciços de cobre, chumbo e zinco, com prata e ouro subordinados, bem como mineralizações de tungstênio e urânio. Vários estudos, compreendendo turmalinitos, rochas com turmalina e veios de quartzo e turmalina, objetivaram associar as características químicas da turmalina com as ocorrências minerais encontradas nas rochas hospedeiras.

No Grupo Serra do Itaberaba (Guarulhos, SP), os turmalinitos ocorrem intercalados em rochas mineralizadas em ouro e sulfetos (pirita + pirrotita + calcopirita) da seqüência metavulcano-sedimentar da Formação Morro da Pedra Preta (Juliani, 1993; Beljavskis, 2003). Este trabalho objetiva verificar a possível correlação entre a composição química da turmalina de turmalinitos com as mineralizações da Formação Morro da Pedra Preta, de forma a obter parâmetros geoquímicos que possam servir como indicadores da potencialidade metalogenética dessa unidade, assim contribuindo para trabalhos de prospecção mineral, não somente no Grupo Serra do Itaberaba, como também em outras seqüências metavulcano-sedimentares, notadamente as meso- e neoproterozóicas do Cinturão Ribeira.

\section{CONTEXTO GEOLÓGICO}

O Grupo Serra do Itaberaba (Juliani et al., 1986) constitui uma seqüência metavulcano-sedimentar cuja distribuição é limitada pelas zonas de cisalhamento de Itu-Jundiuvira, Taxaquara e do Rio Jaguari (Figuras 1a e 1b). O Grupo é composto por três formações, denominadas Morro da Pedra Preta, Nhanguçu e Pirucaia (Juliani, 1993; Juliani e Beljavskis, 1995). A unidade basal (Formação Morro da Pedra Preta) é formada predominantemente por metabasaltos (N-MORB), metabrechas, metatufos e rochas metavulcanoclásticas de composições básica, intermediária e ácida. Xistos de granulação fina a grossa, comumente com leitos de metachert e grafitosos intercalados, são geralmente formados por biotita, granada, muscovita, estaurolita e pouco quartzo, podendo conter, ainda, cianita, sillimanita, andalusita, cordierita, grafita, óxidos de ferro e manganês, e sulfetos. Subordinadamente ocorrem pequenas intrusões de andesito, dacito, riodacito e riolito metamorfizadas, rochas calciossilicáticas, formações ferríferas de facies silicato e óxido (com magnetita ou hematita) e marunditos. A Formação Nhanguçu, formada em ambiente de retroarco, recobre a anterior e é formada por xistos ferro-manganesíferos, por vezes calciossilicáticos, com lentes de anfibolitos, rochas calciossilicáticas e mármores na base. Sobre os xistos ferromanganesíferos ocorrem xistos finos, bandados a laminados, com lentes de quartzitos, formados por muscovita, clorita, andalusita e magnetita. A Formação Pirucaia, depositada em ambiente litorâneo, corresponde às facies marginais da Formação Nhanguçu e é constituída quase que exclusivamente por xistos quartzosos e quartzitos, comumente com zircão detrítico.

O Grupo Serra do Itaberaba foi afetado por dois eventos metamórficos regionais. O primeiro deles, do tipo barroviano, ocorreu no Mesoproterozóico, indo da facies xisto verde transicional para anfibolito $\left(490^{\circ} \mathrm{C}, 4 \mathrm{kbar}\right)$ na parte $\mathrm{SW}$ até a facies anfibolito $\left(650^{\circ} \mathrm{C}, 7 \mathrm{kbar}\right)$ na extremidade $\mathrm{NW}$ (Figura 1b; Juliani et al., 1997, 2000). O segundo evento foi de baixa pressão e ocorreu no Neoproterozóico. O grau 


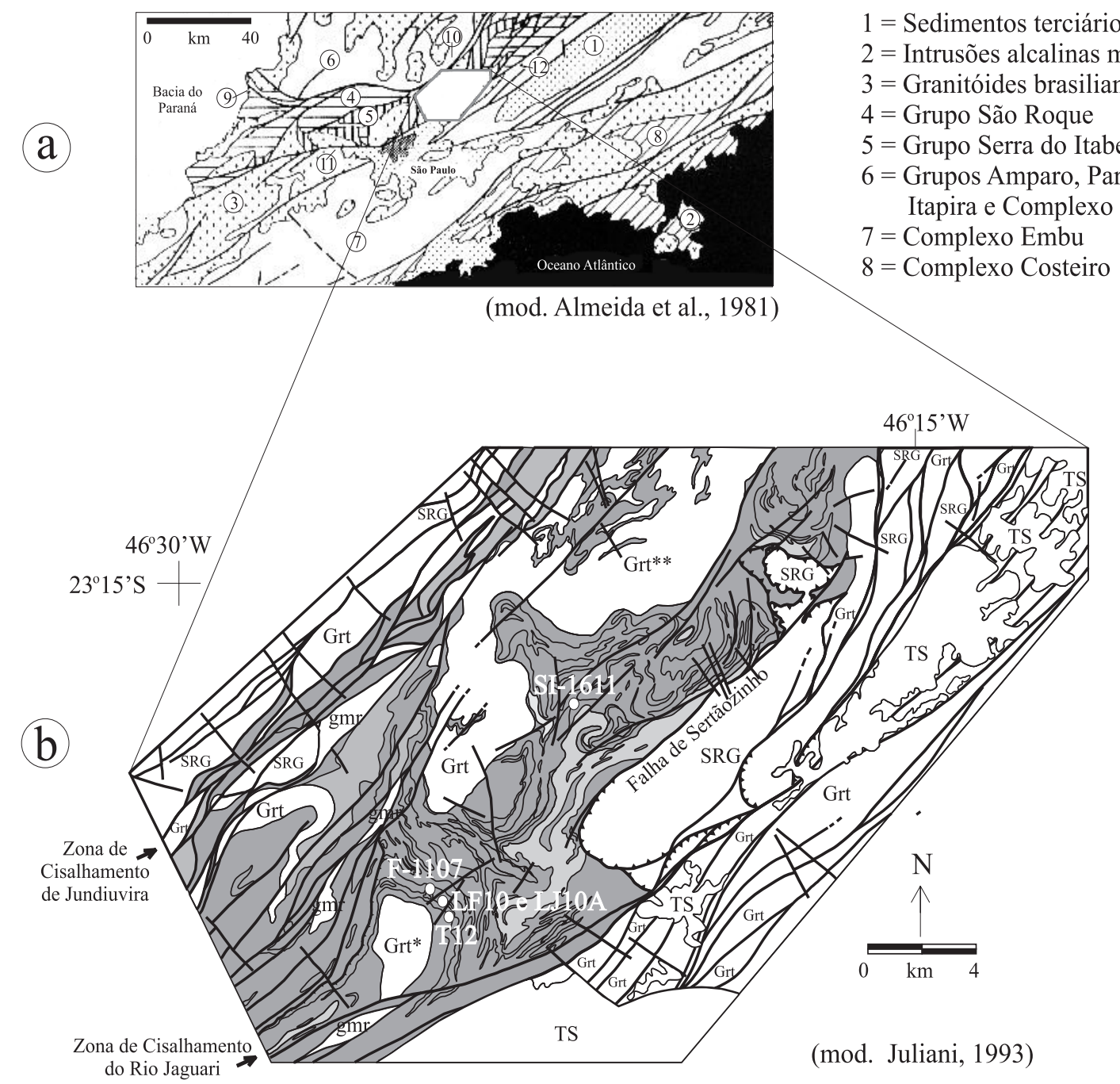

NEOPROTEROZÓICO AO FANEROZÓICO TS Sedimentos terciários

If Zonas de falhas e de cisalhamento

Grt Granitóides (* = Pau Pedra;

$* *=$ Serra da Pedra Branca)

\section{NEOPROTEROZÓICO}

SRG Grupo São Roque

\section{MESOPROTEROZÓICO}

GRUPO SERRA DO ITABERABA

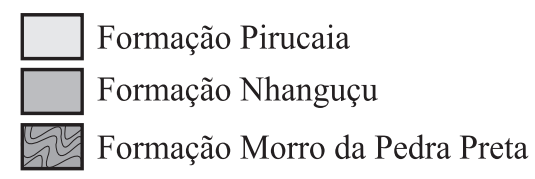

PALEOPROTEROZÓICO E ANTERIOR

$\mathrm{gmr}$ Gnaisses e migmatitos

Figura 1. a) Contexto geológico regional do Grupo Serra do Itaberaba e b) mapa simplificado da região das Serras do Itaberaba e Pedra Branca, com a localização dos pontos de coleta de amostras de turmalinito. 
metamórfico variou entre facies xisto verde $\left(500^{\circ} \mathrm{C}, 4 \mathrm{kbar}\right) \mathrm{e}$ facies anfibolito $\left(580^{\circ} \mathrm{C}, 4,7 \mathrm{kbar}\right)$, sendo ainda responsável pelo retrometamorfismo em facies xisto verde observado na maioria das rochas da área (Juliani et al., 1997, 2000).

\section{TURMALINITOS DA FORMAÇÃO MORRO DA PEDRA PRETA}

Encontram-se leitos delgados de turmalinito na Formação Nhanguçu, mas é na Formação Morro da Pedra Preta que se destacam os corpos de turmalinitos e as principais ocorrências de pirita, pirrotita, calcopirita e ouro.

$\mathrm{Na}$ Figura $1 \mathrm{~b}$ estão localizados os pontos amostrados de turmalinito da Formação Morro da Pedra Preta, descritos a seguir.

\section{Em associação com anfibolitos, metatufos e rochas metassedimentares, com contribuição de rochas calciossilicáticas (SI-1611)}

No local indicado pela sigla SI-1611 (Figura 1b) ocorrem quartzo-sericita xistos, rochas calciossilicáticas, anfibolitos, metatufos e metabrechas com turmalinitos associados. Os anfibolitos são formados por hornblenda e plagioclásio, podendo conter quartzo. Os metatufos e metabrechas têm composição básica e constituem-se de 70 - $80 \%$ em volume de fragmentos, quase sempre angulosos, com granulação variando entre 0,2 e $2 \mathrm{~cm}$. Esses fragmentos foram, em sua maioria, de basaltos e, subordinadamente, de andesito e dacito (Juliani, 1993).

Turmalina de granulação fina compõe mais de $40 \%$ em volume do hornblenda turmalinito SI-1611, que apresenta textura nematoblástica e estrutura microlaminada, caracterizada pela alternância de leitos ricos em quartzo e hornblenda com outros constituídos por turmalina (Figura 2a). Estruturas sedimentares pretéritas, como marcas de onda ou de pressão, são reconhecidas nos leitos ricos em turmalina (Figura 2c). Ao microscópio, a turmalina é verde-escura, com tons acastanhados. Os cristais estão orientados paralelamente aos leitos e são cortados subparalelamente pela foliação metamórfica $S_{1}$, que recristaliza e reorienta parte deles.

A turmalina também compõe agregados filamentosos e coroas ao redor de quartzo, texturas estas sugestivas de precipitação química em ambientes saturados (Juliani, 1993; segundo Ethier e Campbell, 1977). O quartzo está estirado e recristalizado pela $S_{1}$, exibindo extinção fortemente ondulante e contatos interlobados. Hornblenda ocorre como cristais anhédricos a euhédricos alongados concentrados nos leitos da $\mathrm{S}_{0}$. Sillimanita pode ocorrer como mineral acessório, juntamente com pirita e calcopirita. Biotita, com epídoto muito fino nas bordas, é rara.

\section{Em associação com rochas metassedimentares (F-1107)}

As rochas metassedimentares que hospedam esta ocorrência constituem camadas intercaladas em metabasaltos, metabrechas e metatufos básicos e estão associadas a xistos grafitosos ou manganesíferos e leitos de metachert. As rochas metassedimentares apresentam composições muito variadas, mas predominam biotita-muscovita xisto e muscovita-sericita xisto.

O turmalinito representado pela amostra F-1107 faz parte de um leito de metachert e é constituído por turmalina (40 - 65\%) e quartzo (50 - 30\%). A turmalina concentra-se em delgados leitos que se alternam com outros onde predomina quartzo. Os leitos podem estar dobrados e seccionados por microveios. Ocorrem clastos do tipo rip-up (Figura 2b), tal qual descritos por Slack et al. (1984) na mina Black Prince em Broken Hill (Austrália) e por Bone (1988) na área de Rum Jungle (Austrália), indicativos da origem sin-sedimentar.

A turmalina forma cristais zonados, orientados segundo a foliação $S_{1}$ (Figura 2d). Às vezes, encontram-se dobrados intrafolialmente, deformação esta que causa sua recristalização e reorientação parcial segundo a $S_{2}$ (Juliani, 1993).

O quartzo é microcristalino, tem contatos irregulares, extinção ondulante e mostra-se recristalizado em grãos menores. Microfraturas com remobilização de quartzo, turmalina e minerais opacos são comuns. Pirrotita e, em menor volume, pirita e calcopirita podem alcançar 3\% em volume da rocha.

\section{Em associação com metandesitos e metarriolitos (LF-10 e LJ10-A)}

Estas amostras foram coletadas nas lavras de ouro do final do século XVI a meados do século XVII. O metachert mineralizado em ouro forma camadas de 15 a $60 \mathrm{~cm}$ de espessura no topo de corpos de metabrechas, metaglomerados vulcânicos e metatufos de composição variando de andesítica a riodacítica. Estas camadas estão capeadas por metatufos básicos e xistos finos calciossilicáticos que gradam para rochas calciossilicáticas e metapelitos. O metachert é constituído por quartzo, que às vezes perfaz $100 \%$ do volume da rocha, e por minerais opacos, turmalina e clorita acessórios.

O turmalinito, constituído por turmalina ( 40 - $65 \%$ ) e quartzo (35-60\%), ocorre como delgados leitos, geralmente descontínuos, finamente laminados, intercalados ou posicionados na borda da camada de metachert. São comuns dobras intrafoliais do primeiro evento deformacional e, localmente, podem mostrar-se deformadas pela $\mathrm{S}_{2}$ e intensamente crenuladas pela foliação $\mathrm{S}_{3}$.

Ao microscópio, a turmalina é zonada, de cor verdeazulada, às vezes, marrom-clara, e os cristais formam agre- 


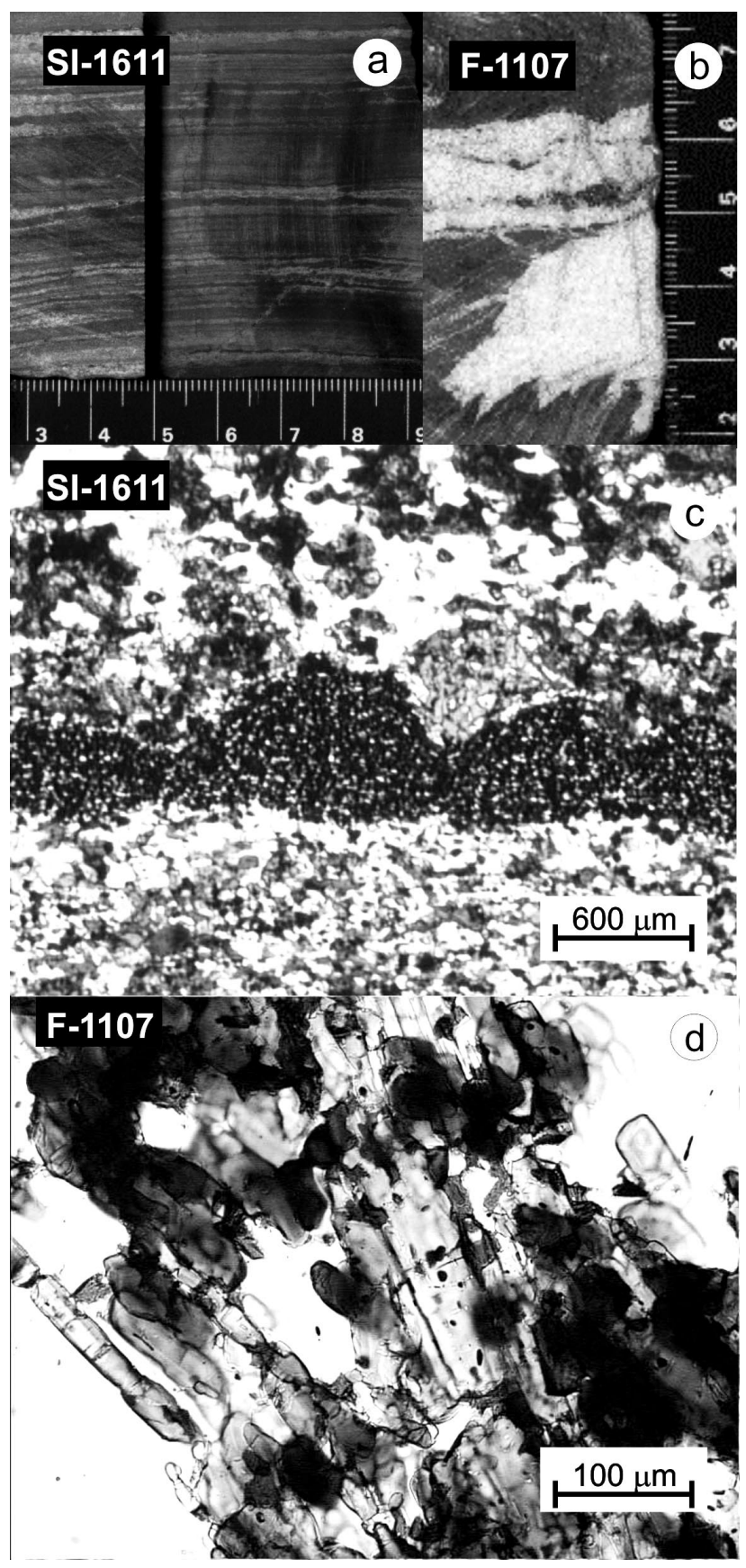

Figura 2. Fotografias com detalhes característicos dos turmalinitos da Formação Morro da Pedra Preta. a) Estrutura microlaminada, caracterizada pela alternância de leitos ricos em quartzo e hornblenda com outros compostos por turmalina. b) Dobras e clastos rip-up. c) Marcas de onda ou de pressão em leito rico em turmalina. d) Cristais zonados de turmalina. gados ou acículas isoladas. Comumente observam-se cristais dobrados e fraturados e as relações texturais com as foliações metamórficas indicam cristalização pré-S $\mathrm{S}_{1} \mathrm{O}$ quartzo é microcristalino e inequigranular. Nos leitos onde aparece com granulação mais fina, concentram-se turmalina e minerais opacos. O quartzo mostra-se deformado, com forte extinção ondulante e, por vezes, orienta-se segundo uma ou mais foliações. Os contatos entre os grãos, freqüentemente recristalizados, são irregulares ou lobados. São também comuns delgadíssimos veios de quartzo deformados, possivelmente diagenéticos ou sin-metamórficos, cujos grãos apresentam inclusões finas de minerais opacos e apatita.

\section{Em associação com metatufos básicos (T-12)}

$\mathrm{Na}$ área da ocorrência, os metatufos básicos constituem corpos com limitadas extensões laterais. Correspondem a hornblenda xisto, hornblenda-biotita xisto e biotitahornblenda xisto bandados, às vezes com leitos de metachert. O turmalinito ocorre como bandas pouco espessas, geralmente associado a zonas ricas em leitos de metachert.

O turmalinito contém 55 - 70\% de turmalina e 30 - 45\% de quartzo, além de epidoto, pirita, pirrotita e calcopirita acessórios. Lâminas ricas em turmalina alternam-se com outras ricas em quartzo, e o conjunto comumente está microdobrado. Microfraturas preenchidas por quartzo, turmalina e óxidos/ hidróxidos de ferro são também comuns.

A turmalina forma agregados ou cristais aciculares isolados em meio a quartzo de granulação $<0,105 \mathrm{~mm}$. Está orientada segundo a foliação $\mathrm{S}_{1}$ e, por vezes, dobrada intrafolialmente. Comumente a cor dos cristais zonados varia de marrom na borda a verde-azulado no centro.

\section{COMPOSIÇÃO QUÍMICA DA TURMALINA}

As análises de turmalina foram realizadas no Laboratório de Microssonda Eletrônica do Instituto de Geociências da Universidade de São Paulo (IGc - USP), equipado com uma microssonda eletrônica JEOL modelo JXA-8600.

Os resultados analíticos são apresentados na Tabela 1. A turmalina dos turmalinitos F-1107, LF-10, LJ10-A e T-12 é mais rica em $\mathrm{Al}_{2} \mathrm{O}_{3}$ e $\mathrm{Na}_{2} \mathrm{O}$ que a da amostra $\mathrm{SI}-1611$ que, por sua vez, é mais rica em $\mathrm{MgO}$ (média de 8,76\%), $\mathrm{CaO}$ (média de $3,37 \%$ ), $\mathrm{TiO}_{2}$ (média de $0,83 \%$ ) e $\mathrm{F}$ (entre $0,3-0,4 \%$ ). A composição da turmalina da amostra T-12 constitui dois grupos, um com $\mathrm{FeO}>8,4 \%$ e outro com $\mathrm{FeO}<8,3 \%$. A turmalina do grupo com $\mathrm{FeO}>8,4 \%$ é relativamente mais pobre em $\mathrm{SiO}_{2}$ e $\mathrm{MgO}$, e mais rica em $\mathrm{TiO}_{2}(0,38-0,59 \%)$ e $\mathrm{CaO}(0,36-0,60 \%)$, ao passo que a do grupo com $\mathrm{FeO}<8,3 \%$ é mais rica em $\mathrm{MgO}(6,3-7,0 \%)$. 
Tabela 1. Composição química (\% em peso) obtida por microssonda eletrônica da turmalina de turmalinitos da Formação Morro da Pedra Preta.

\begin{tabular}{|c|c|c|c|c|c|c|c|c|c|c|c|c|c|}
\hline Amostra & LF-10-1 & LF-10-2 & LF-10-3 & LF-10-4 & LF-10-5 & LF-10-6 & LF-10-7 & LF-10-8 & LJ10A-1 & LJ10A-2 & LJ10A-3 & LJ10A-4 & LJ10A-5 \\
\hline $\mathrm{SiO}_{2}$ & 34,93 & 34,22 & 35,01 & 34,57 & 35,11 & 35,04 & 34,77 & 34,33 & 34,54 & 35,34 & 35,37 & 34,68 & 34,66 \\
\hline $\mathrm{TiO}_{2}$ & 0,57 & 0,45 & 0,23 & 0,52 & 0,45 & 0,41 & 0,55 & 0,60 & 0,84 & 0,33 & 0,04 & 0,07 & 0,26 \\
\hline $\mathrm{Al}_{2} \mathrm{O}_{3}$ & 29,78 & 30,67 & 30,28 & 29,67 & 31,06 & 30,35 & 30,97 & 29,74 & 30,09 & 31,65 & 31,93 & 31,26 & 31,05 \\
\hline $\mathrm{Cr}_{2} \mathrm{O}_{3}$ & 0,00 & 0,00 & 0,00 & 0,04 & 0,00 & 0,00 & 0,00 & 0,00 & 0,00 & 0,00 & 0,00 & 0,00 & 0,00 \\
\hline $\mathrm{FeO}$ & 13,52 & 11,65 & 12,19 & 12,43 & 11,07 & 11,87 & 11,85 & 13,18 & 12,39 & 10,71 & 10,93 & 12,10 & 11,85 \\
\hline $\mathrm{MnO}$ & 0,00 & 0,00 & 0,04 & 0,00 & 0,00 & 0,00 & 0,00 & 0,00 & 0,05 & 0,00 & 0,03 & 0,00 & 0,07 \\
\hline $\mathrm{MgO}$ & 4,35 & 4,68 & 4,53 & 4,63 & 4,89 & 4,88 & 4,68 & 4,42 & 4,59 & 4,65 & 4,64 & 3,96 & 4,20 \\
\hline $\mathrm{CaO}$ & 0,94 & 0,67 & 0,45 & 0,74 & 0,48 & 0,66 & 0,61 & 0,84 & 0,70 & 0,48 & 0,21 & 0,33 & 0,35 \\
\hline $\mathrm{Na}_{2} \mathrm{O}$ & 2,11 & 2,04 & 2,19 & 2,26 & 1,98 & 2,13 & 2,12 & 1,99 & 2,11 & 2,04 & 1,92 & 2,09 & 2,02 \\
\hline $\mathrm{K}_{2} \mathrm{O}$ & 0,02 & 0,03 & 0,00 & 0,02 & 0,03 & 0,00 & 0,00 & 0,00 & 0,02 & 0,00 & 0,00 & 0,03 & 0,03 \\
\hline$F$ & 0,00 & 0,17 & 0,00 & 0,00 & 0,00 & 0,00 & 0,17 & 0,14 & 0,00 & 0,00 & 0,15 & 0,00 & 0,00 \\
\hline $\mathrm{Cl}$ & 0,00 & 0,00 & 0,00 & 0,00 & 0,00 & 0,00 & 0,01 & 0,00 & 0,00 & 0,00 & 0,03 & 0,00 & 0,00 \\
\hline Total & 86,22 & 84,58 & 84,92 & 84,88 & 85,07 & 85,34 & 85,73 & 85,24 & 85,34 & 85,19 & 85,26 & 84,51 & 84,48 \\
\hline & \multicolumn{13}{|c|}{ Íons calculados na base de 31 átomos de oxigênio e 3 átomos de boro } \\
\hline $\mathrm{B}$ & 3 & 3 & 3 & 3 & 3 & 3 & 3 & 3 & 3 & 3 & 3 & 3 & 3 \\
\hline $\mathrm{F}$ & 0 & 0,092 & 0 & 0 & 0 & 0 & 0,091 & 0,076 & 0 & 0 & 0,008 & 0 & 0 \\
\hline $\mathrm{Cl}$ & 0 & 0 & 0 & 0 & 0 & 0 & 0,003 & 0 & 0 & 0 & 0,001 & 0 & 0 \\
\hline Si total & 5,933 & 5,850 & 5,977 & 5,934 & 5,940 & 5,948 & 5,863 & 5,880 & 5,893 & 5,950 & 5,937 & 5,935 & 5,931 \\
\hline Al total & 5,964 & 6,181 & 6,095 & 6,004 & 6,195 & 6,073 & 6,157 & 6,005 & 6,051 & 6,282 & 6,319 & 6,307 & 6,263 \\
\hline Fe total & 1,921 & 1,666 & 1,741 & 1,784 & 1,566 & 1,685 & 1,671 & 1,888 & 1,768 & 1,508 & 1,535 & 1,731 & 1,696 \\
\hline$\overline{\mathrm{SiT}}$ & 5,933 & 5,850 & 5,977 & 5,934 & 5,940 & 5,948 & 5,863 & 5,880 & 5,893 & 5,950 & 5,937 & 5,935 & 5,931 \\
\hline AIT & 0,067 & 0,150 & 0,023 & 0,066 & 0,060 & 0,052 & 0,137 & 0,120 & 0,107 & 0,050 & 0,063 & 0,065 & 0,069 \\
\hline$\overline{\mathrm{AlZ}}$ & 5,897 & 6,000 & 6,000 & 5,939 & 6,000 & 6,000 & 6,000 & 5,886 & 5,944 & 6,000 & 6,000 & 6,000 & 6,000 \\
\hline$\overline{\text { AIY }}$ & 0,000 & 0,032 & 0,072 & 0,000 & 0,134 & 0,021 & 0,021 & 0,000 & 0,000 & 0,232 & 0,256 & 0,242 & 0,194 \\
\hline SiY & 0,000 & 0,000 & 0,000 & 0,000 & 0,000 & 0,000 & 0,000 & 0,000 & 0,000 & 0,000 & 0,000 & 0,000 & 0,000 \\
\hline $\mathrm{Ti}$ & 0,073 & 0,058 & 0,030 & 0,067 & 0,057 & 0,052 & 0,070 & 0,077 & 0,108 & 0,042 & 0,005 & 0,010 & 0,033 \\
\hline $\mathrm{Mg}$ & 1,101 & 1,192 & 1,153 & 1,184 & 1,233 & 1,234 & 1,176 & 1,128 & 1,167 & 1,167 & 1,161 & 1,009 & 1,070 \\
\hline $\mathrm{Cr}$ & 0,000 & 0,000 & 0,000 & 0,005 & 0,000 & 0,000 & 0,000 & 0,000 & 0,000 & 0,000 & 0,000 & 0,000 & 0,000 \\
\hline $\mathrm{Fe} 2$ & 1,817 & 1,666 & 1,741 & 1,723 & 1,566 & 1,685 & 1,671 & 1,774 & 1,712 & 1,508 & 1,535 & 1,731 & 1,696 \\
\hline $\mathrm{Fe} 3$ & 0,103 & 0,000 & 0,000 & 0,061 & 0,000 & 0,000 & 0,000 & 0,114 & 0,056 & 0,000 & 0,000 & 0,000 & 0,000 \\
\hline $\mathrm{Mn}$ & 0,000 & 0,000 & 0,006 & 0,000 & 0,000 & 0,000 & 0,000 & 0,000 & 0,007 & 0,000 & 0,004 & 0,000 & 0,010 \\
\hline Ytotal & 3,095 & 2,948 & 3,001 & 3,041 & 2,991 & 2,993 & 2,938 & 3,094 & 3,050 & 2,949 & 2,961 & 2,992 & 3,003 \\
\hline$\overline{\mathrm{Ca}}$ & 0,171 & 0,123 & 0,082 & 0,136 & 0,087 & 0,120 & 0,110 & 0,154 & 0,128 & 0,086 & 0,037 & 0,060 & 0,064 \\
\hline $\mathrm{Na}$ & 0,695 & 0,676 & 0,725 & 0,752 & 0,649 & 0,701 & 0,693 & 0,661 & 0,699 & 0,665 & 0,626 & 0,693 & 0,671 \\
\hline $\mathrm{K}$ & 0,004 & 0,007 & 0,000 & 0,004 & 0,006 & 0,000 & 0,000 & 0,000 & 0,005 & 0,000 & 0,000 & 0,006 & 0,007 \\
\hline $\operatorname{vacX}$ & 0,130 & 0,195 & 0,193 & 0,107 & 0,257 & 0,179 & 0,197 & 0,185 & 0,168 & 0,249 & 0,337 & 0,241 & 0,258 \\
\hline Total Cátions & 15,862 & 15,752 & 15,808 & 15,872 & 15,734 & 15,814 & 15,741 & 15,794 & 15,826 & 15,700 & 15,624 & 15,751 & 15,745 \\
\hline$\overline{\mathrm{R} 1}$ & 0,87 & 0,80 & 0,81 & 0,89 & 0,74 & 0,82 & 0,80 & 0,82 & 0,83 & 0,75 & 0,66 & 0,75 & 0,74 \\
\hline $\mathrm{R} 2$ & 3,02 & 2,86 & 2,89 & 2,97 & 2,80 & 2,92 & 2,85 & 3,02 & 2,89 & 2,68 & 2,70 & 2,74 & 2,78 \\
\hline R3 & 6,06 & 6,26 & 6,13 & 6,09 & 6,27 & 6,14 & 6,25 & 6,11 & 6,20 & 6,34 & 6,33 & 6,32 & 6,31 \\
\hline XAI & 0,00 & 0,11 & 0,11 & 0,03 & 0,21 & 0,09 & 0,11 & 0,00 & 0,09 & 0,29 & 0,26 & 0,26 & 0,24 \\
\hline $\mathrm{Fe} /(\mathrm{Fe}+\mathrm{Mg})$ & 0,64 & 0,58 & 0,60 & 0,60 & 0,56 & 0,58 & 0,59 & 0,63 & 0,60 & 0,56 & 0,57 & 0,63 & 0,61 \\
\hline
\end{tabular}




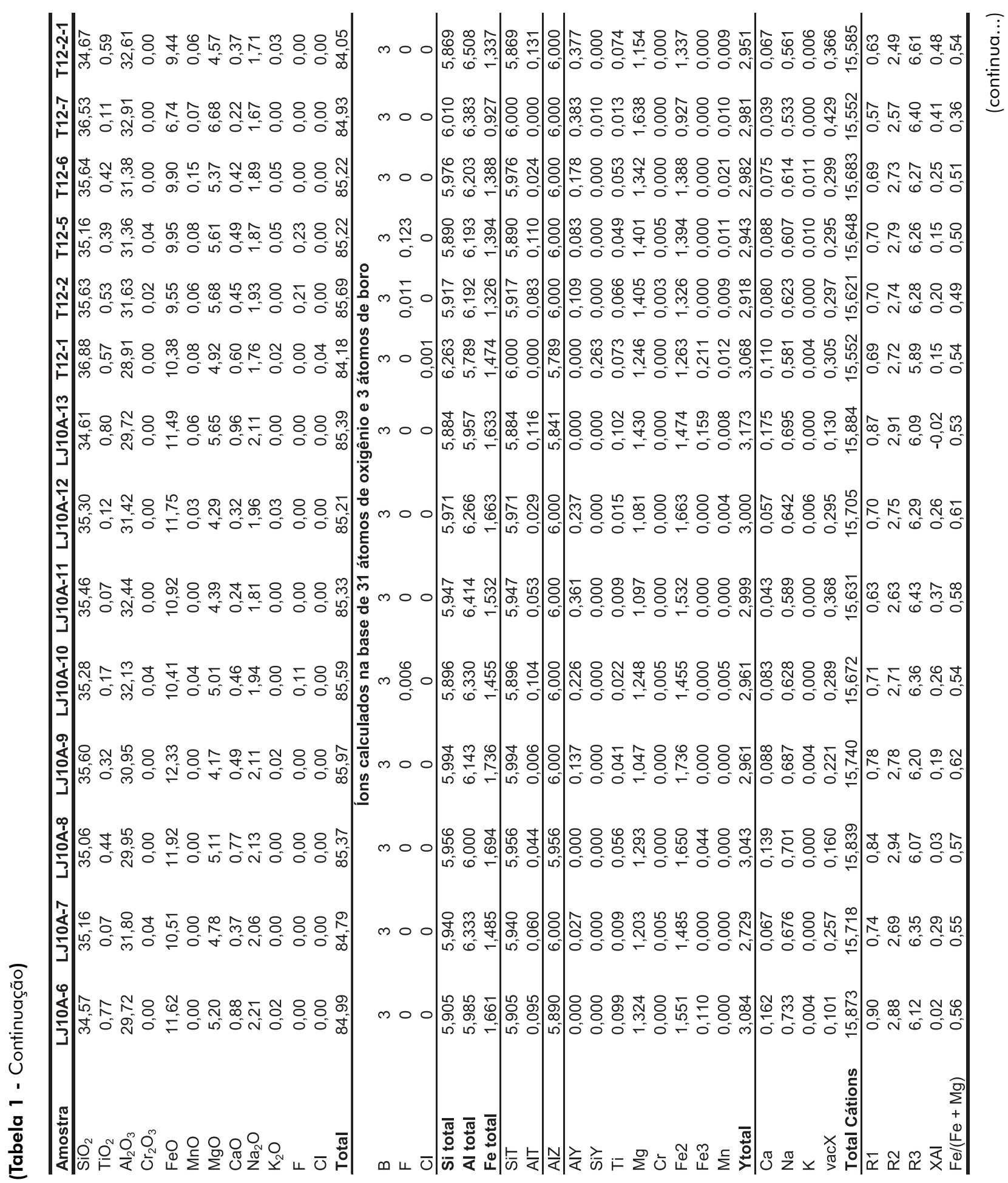


(Tabela 1 - Continuação)

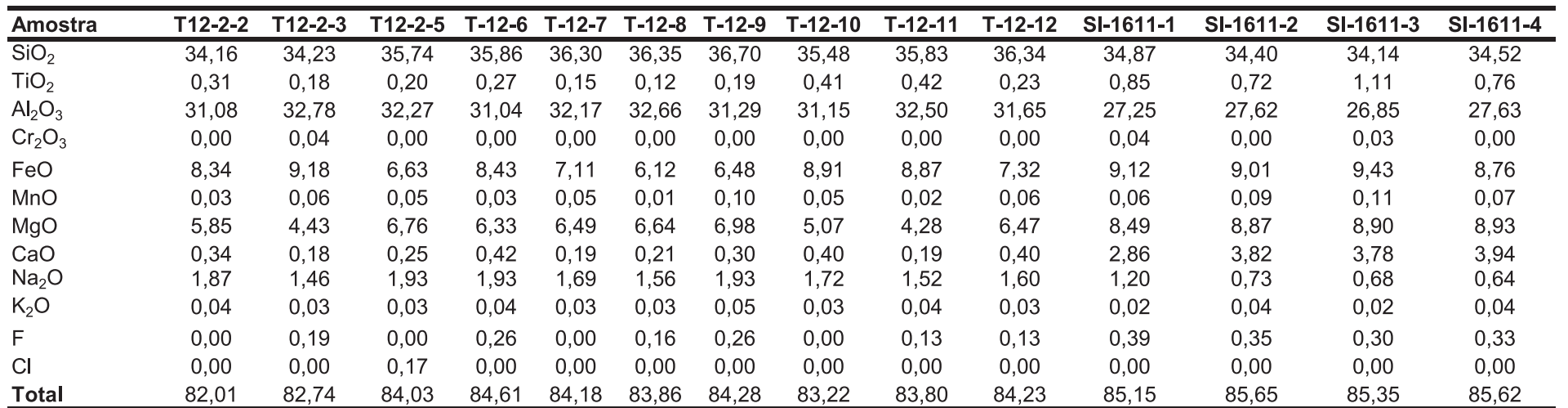

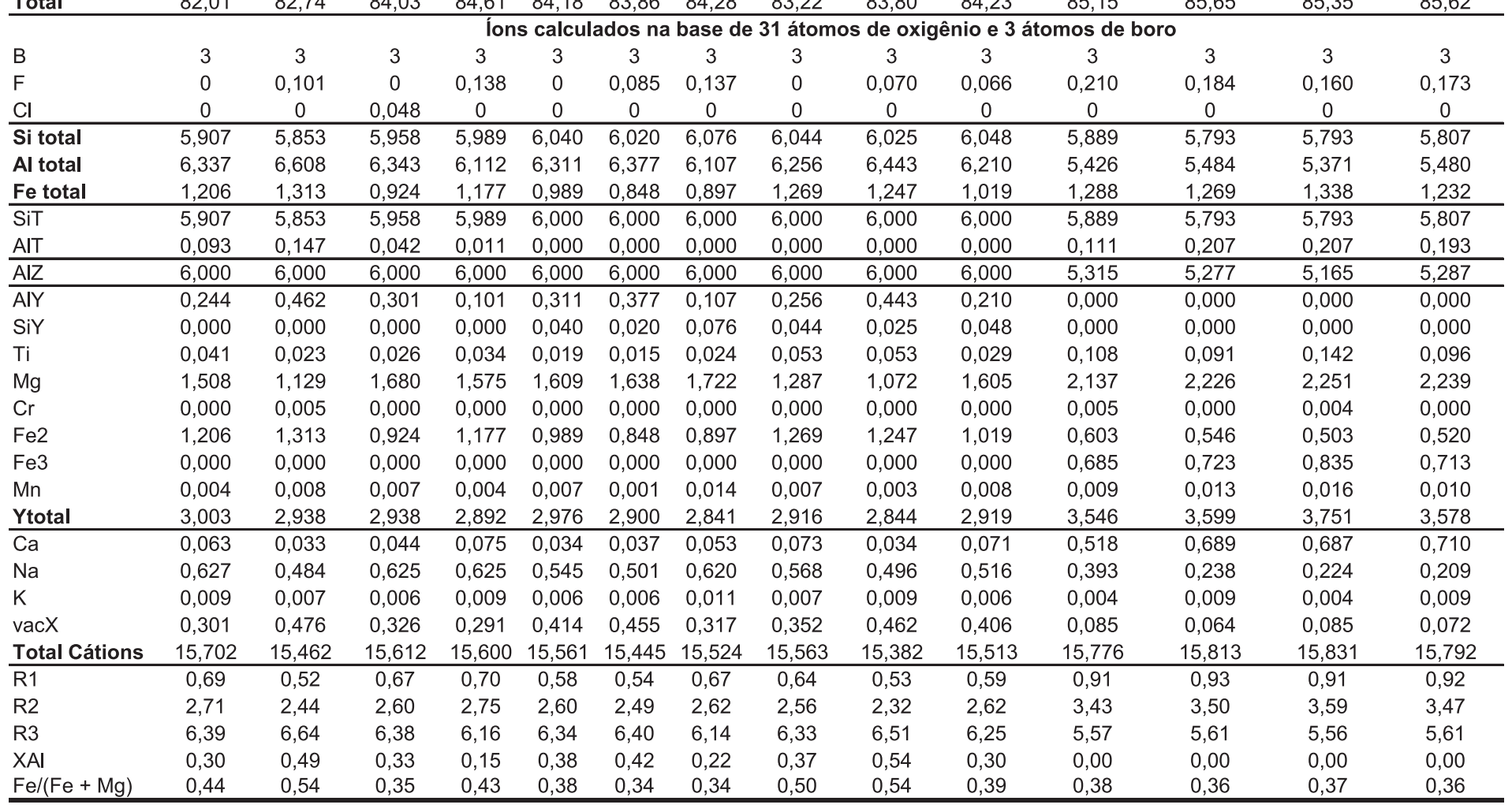




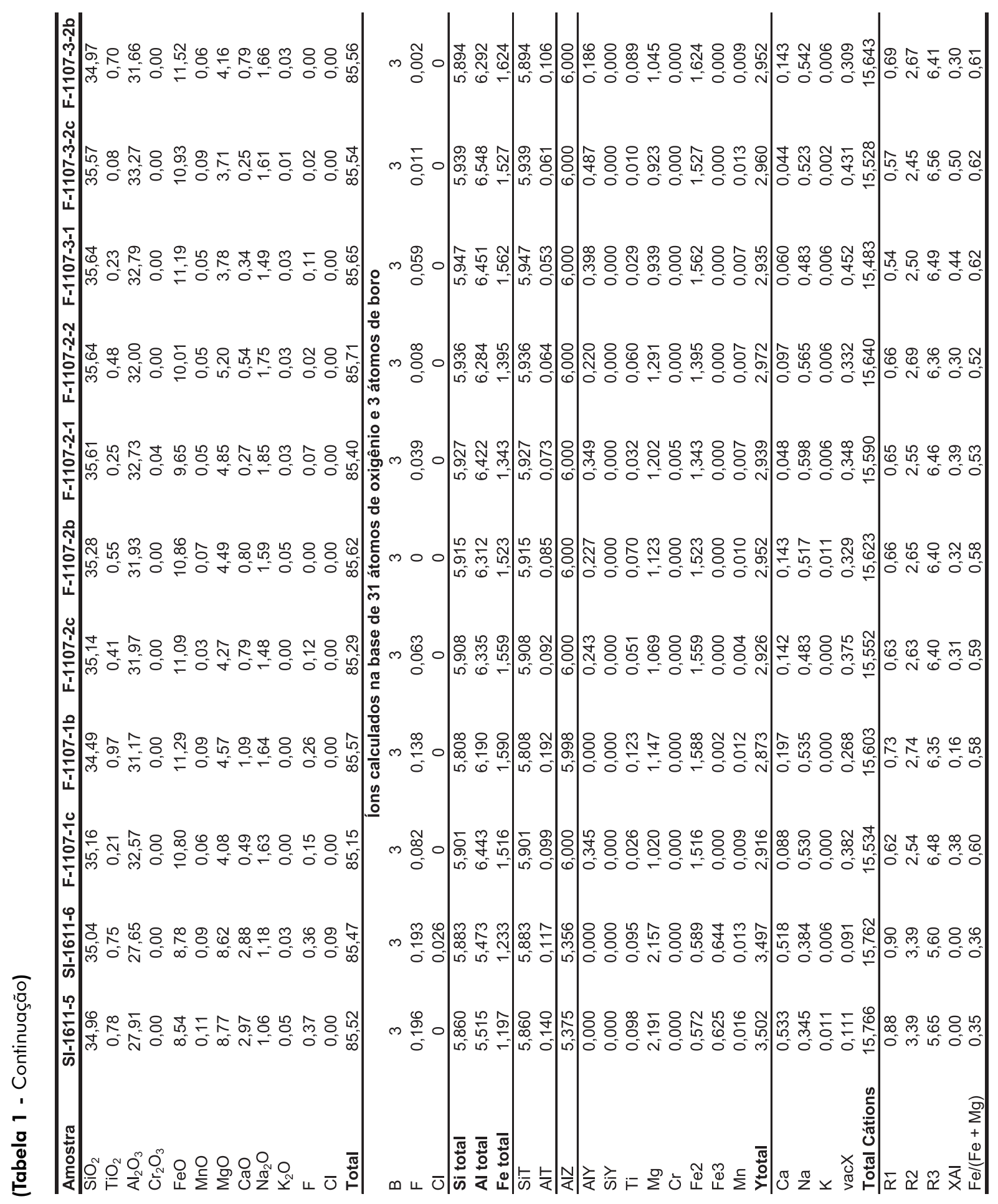


A fórmula estrutural da turmalina,

$\mathrm{XY}_{3} \mathrm{Z}_{6}\left(\mathrm{BO}_{3}\right)_{3} \mathrm{Si}_{6} \mathrm{O}_{18}(\mathrm{OH}, \mathrm{F}, \mathrm{Cl}, \mathrm{O})$,

foi calculada assumindo 3 átomos de boro e 31 átomos de oxigênio por fórmula unitária (a.p.f.u.). Utilizou-se o programa Microsoft Excel para os cálculos, assumindo-se para $\mathrm{Fe}^{3+}$, conforme Yavuz (1997), a ocupação plena das posições T e Z:

$$
\begin{aligned}
& \mathrm{T}=\mathrm{Si}+\mathrm{Al}^{\mathrm{IV}}=6 \\
& \mathrm{Z}=\mathrm{Al}^{\mathrm{V}}+\mathrm{Fe}^{3+}=6 \\
& \mathrm{X}=\mathrm{Na}+\mathrm{Ca}+\mathrm{K}, \text { sendo a vacância em } \mathrm{X} \text { ou, simplifica- } \\
& \quad \text { damente, } \operatorname{vacX}=1-(\mathrm{Na}+\mathrm{Ca}+\mathrm{K}) \\
& \mathrm{Y}=\mathrm{Fe}+\mathrm{Mg}+\mathrm{Mn}+\mathrm{Al}_{\mathrm{Y}}+\mathrm{Si}_{\mathrm{Y}}+\mathrm{Ti}+\mathrm{Cr}+\mathrm{V}
\end{aligned}
$$

Yavuz (1997) recomenda o cálculo dos parâmetros R1, R2 e R3 segundo:

$$
\begin{aligned}
& \mathrm{R} 1=\mathrm{Na}+\mathrm{Ca} \\
& \mathrm{R} 2=\mathrm{Fe}_{\text {total }}+\mathrm{Mg} \\
& \mathrm{R} 3=\mathrm{Al}_{\text {total }}+1,33 \mathrm{Ti} \\
& \mathrm{XAl}=\mathrm{R} 3+\mathrm{Si}_{\text {total }}-12
\end{aligned}
$$

O diagrama binário $\mathrm{Ca} /(\mathrm{Ca}+\mathrm{Na})$ vs. $\mathrm{Fe}_{\text {total }} /\left(\mathrm{Fe}_{\text {total }}+\mathrm{Mg}\right)$ (Figura 3a) indica que a turmalina da amostra SI-1611 tem como componente predominante a uvita,

$$
\mathrm{CaMg}_{3}\left(\mathrm{MgAl}_{5}\right)\left(\mathrm{BO}_{3}\right)_{3} \mathrm{Si}_{6} \mathrm{O}_{18}(\mathrm{OH})_{4} \text {, }
$$

enquanto na turmalina com $\mathrm{FeO}>8,4 \%$ da amostra T-12 predomina a componente dravita,

$$
\begin{aligned}
& \mathrm{NaMg}_{3} \mathrm{Al}_{6}\left(\mathrm{BO}_{3}\right)_{3} \mathrm{Si}_{6} \mathrm{O}_{18}(\mathrm{OH})_{4} \text {, sobre schorlita, } \\
& \mathrm{NaFe}_{3} \mathrm{Al}_{6}\left(\mathrm{BO}_{3}\right)_{3} \mathrm{Si}_{6} \mathrm{O}_{18}(\mathrm{OH})_{4},
\end{aligned}
$$

ocorrendo o oposto com a turmalina com $\mathrm{FeO}<8,3 \%$ da mesma amostra. A turmalina das amostras F-1107, LF-10 e LJ10-A apresenta comportamento semelhante ao verificado para a turmalina com $\mathrm{FeO}>8,4 \%$ da amostra $\mathrm{T}-12$, sendo que a razão $\mathrm{Fe}_{\text {total }} /\left(\mathrm{Fe}_{\text {total }}+\mathrm{Mg}\right)$ varia de 0,50 a 0,64 .

$\mathrm{O}$ diagrama ternário $\mathrm{Ca}-\operatorname{vacX}-\mathrm{Na}+\mathrm{K}$ (a.p.f.u.) de Hawthorne e Henry (1999) classifica a turmalina da amostra SI-1611 como de composição compatível com o "grupo cálcico", e as das demais amostras, com o "grupo alcalino" (Figura 3b).

É interessante notar que a turmalina da amostra SI-1611 e a turmalina com $\mathrm{FeO}<8,3 \%$ da amostra T-12 apresentam valores de $\mathrm{Fe}_{\text {total }} /\left(\mathrm{Fe}_{\text {total }}+\mathrm{Mg}\right)$ semelhantes, diferenciandose pelos conteúdos de $\mathrm{CaO}$. Mesmo sendo a mais pobre em $\mathrm{Na}_{2} \mathrm{O}(0,6-1,3 \%)$, a turmalina da amostra SI-1611 apresenta os valores mais baixos de vacX $(\sim 0,1)$, indicando que há $\mathrm{Ca}$ suficiente para manter a posição $\mathrm{X}$ praticamente preenchida, mesmo sendo pobre em $\mathrm{Na}$. Este fato a distingue da turmalina deficiente em álcalis que ocorre em veios da área Quartzito, descrita por Garda et al. (2003). Essa turmalina, também rica em $\mathrm{Mg}$ e $\mathrm{Cr}$, apresenta composição intermediária entre foitita e magnesiofoitita, sendo o valor de vacX relativamente alto.

A turmalina da amostra SI-1611, além dos baixos valores de vacX (fazendo com que $\mathrm{Na} /(\mathrm{Na}+$ vacX) varie entre $0,72$ e 0,83 - Figura $4 a)$, tem como outras características a deficiência em $\mathrm{Al}$, que resulta em valores de XAl negativos (Tabela 1), e valores de $\mathrm{Fe}^{3+}>0,6$ a.p.f.u.

A turmalina das demais amostras (T12, LF-10, LJ10-A e F-1107) mostra variação do excesso de Al, sendo $0<\mathrm{Al}_{\mathrm{Y}}<0,5$. Para esta turmalina, apesar dos valores de $\mathrm{Ca}$ (a.p.f.u.) não ultrapassarem 0,2 , os $\mathrm{de} \mathrm{Na}+\mathrm{K}$ (a.p.f.u.) variam entre 0,5 e 0,8 , resultando em valores de vacX entre 0,1 e 0,5 . Novamente não se configura a deficiência em álcalis da turmalina de veio, de composição intermediária entre foititamagnesiofoitita, apresentada por Garda et al. (2003). No diagrama R1+R2 vs. R3 (Figura 4b), esta última ocupa a porção mais inferior $(2,9<\mathrm{R} 1+\mathrm{R} 2<3,5)$ do vetor de substituição $\{[] \mathrm{Al}\}\{\mathrm{Na}(\mathrm{Fe}, \mathrm{Mg})\}_{-1}$, onde [ ] representa a vacância em X.

A turmalina da amostra SI-1611 novamente se destaca por plotar ao longo do vetor $[\mathrm{Ca}(\mathrm{Fe}, \mathrm{Mg})][\mathrm{NaAl}]_{-1}$, que indica a substituição de $\mathrm{Al}$ por $\mathrm{Fe}^{3+}$ na posição $\mathrm{Z}$ e de $\mathrm{Na}$ por $\mathrm{Ca}$ na posição X, caracterizando a componente uvita (Figura 4b). Adicionalmente, tem-se F em substituição a $\mathrm{OH}$.

Os diagramas de Henry e Guidotti (1985), apesar de não incluírem explicitamente a composição da turmalina de turmalinitos, indicam as possíveis associações litológicas e ambientes de formação de turmalinitos. No diagrama $\mathrm{Al}-\mathrm{Fe}_{50} \mathrm{Al}_{50}-\mathrm{Mg}_{50} \mathrm{Al}_{50}$ (a.p.f.u., Figura 5a), a turmalina das amostras F-1107, LF-10 e LJ10-A situa-se no limite entre a composição da turmalina dos granitóides pobres em Li e pegmatitos e aplitos associados (campo 2) e de metapelitos e metapsamitos coexistindo ou não com minerais indicativos da saturação em Al (campos 4 e 5). A turmalina das amostras LF-10 e LJ10-A apresenta os teores mais elevados de FeO. A turmalina da amostra T-12, com variações nos teores de Fe e $\mathrm{Mg}$, situa-se no limite composicional de turmalina de metapelitos e metapsamitos, podendo coexistir com minerais indicativos da saturação em Al (campos 4 e 5). A turmalina da amostra SI-1611 tem composição típica da turmalina de rochas ricas em $\mathrm{Fe}^{3+}$ com quartzo e turmalina, associadas a rochas calciossilicáticas e metapelitos (campo 6).

No diagrama $\mathrm{Ca}-\mathrm{Fe}_{\text {total }}-\mathrm{Mg}$ (a.p.f.u., Figura 5b), a turmalina das amostras F-1107, LF-10 e LJ10-A distribuemse nas proximidades do limite composicional da turmalina de granitóides pobres em Li e de pegmatitos e aplitos associados (campo 2) e de metapelitos e metapsamitos pobres 
em $\mathrm{Ca}$ e de rochas com quartzo e turmalina (campo 4). A turmalina da amostra T-12 insere-se predominantemente no campo 4, evidenciando também as variações nos conteúdos de Fe e Mg. A composição da turmalina da amostra SI-1611 restringe-se ao campo 3 , correspondente à turmalina de metapelitos, metapsamitos ricos em $\mathrm{Ca}$ e rochas calciossilicáticas.

\section{AMBIENTE DEPOSICIONAL DOS TURMALINITOS}

Representa-se na Figura 6 um sistema hidrotermal, instalado em fundo oceânico, localizando-se corpos de turmalinitos em relação ao centro de atividade vulcanoexalativa. O esquema é equivalente ao apresentado por

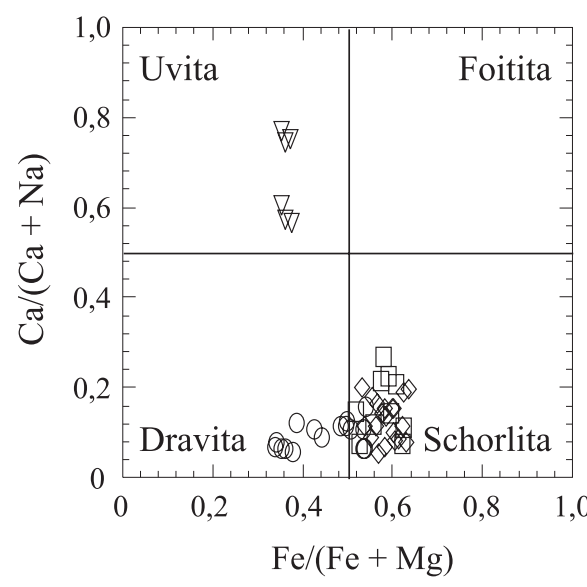

a $\nabla$ SI-1611

O $\mathrm{T} 12$

$\diamond$ LF-10 e LJ10-A

F-1107

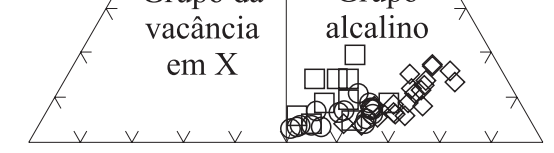

$\operatorname{vacX}$

Figura 3. Classificação da turmalina através dos diagramas: a) $\mathrm{Ca} /(\mathrm{Ca}+\mathrm{Na})$ vs. $\mathrm{Fe} /(\mathrm{Fe}+\mathrm{Mg})$ e b) $\mathrm{Ca}-\mathrm{vacX}-\mathrm{Na}+\mathrm{K}$. Teores em proporções atômicas.

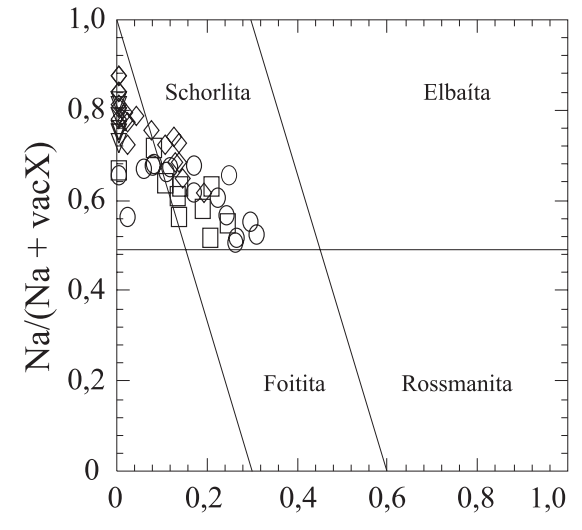

$\mathrm{Al} /(\mathrm{Al}+\mathrm{Fe})$ em $\mathrm{Y}$

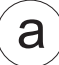

$\nabla$ SI-1611

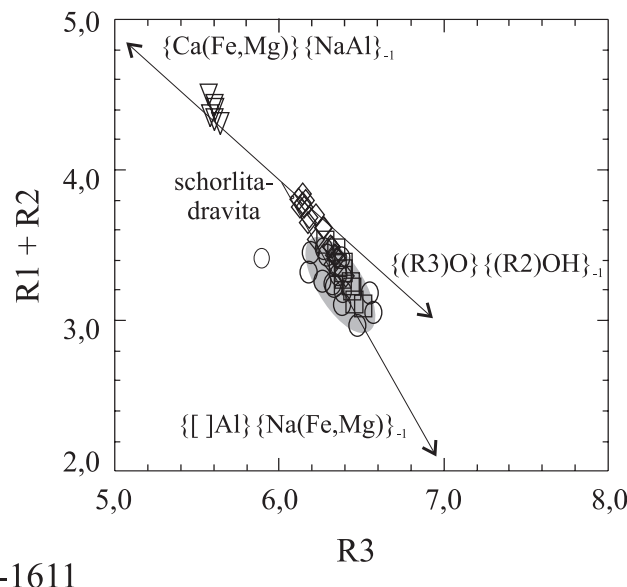

T12

LF-10 e LJ10-A

F-1107

b

Ca

álcico 


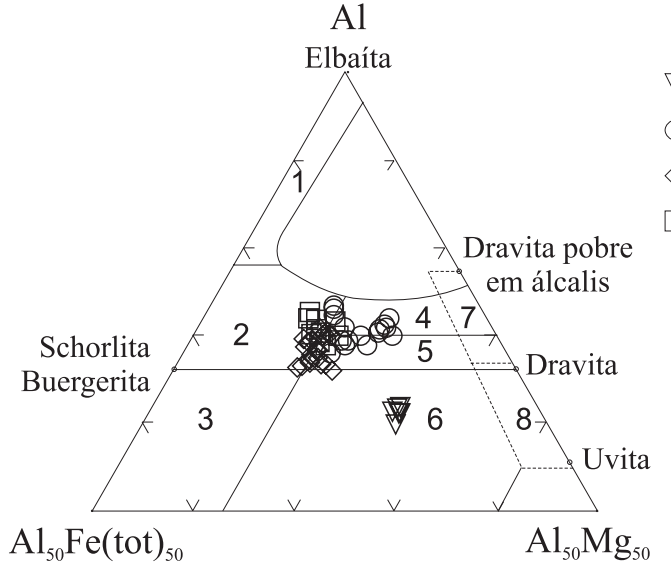

a

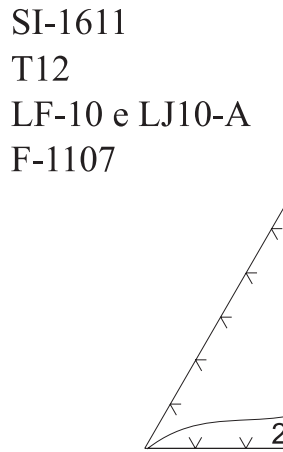

$\mathrm{Fe}(\mathrm{tot})$

Schorlita/Buergerita
$\mathrm{Ca}$

Liddicoatita

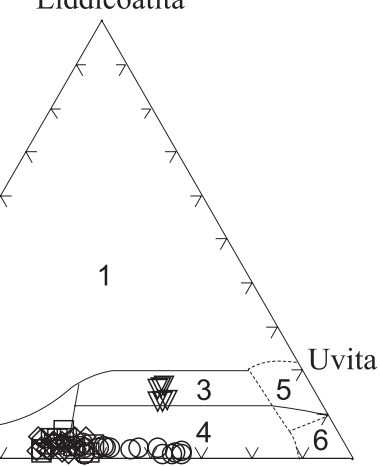

$\mathrm{Mg}$

b

Figura 5. Classificação química (proporção atômica) da turmalina, segundo Henry e Guidotti (1985). Os campos em (a) correspondem à turmalina de: 1. pegmatitos e aplitos de granitóides ricos em Li; 2. granitóides pobres em Li e pegmatitos e aplitos associados; 3. granitos hidrotermalizados ricos em quartzo, sendo a turmalina rica em $\mathrm{Fe}^{3+}$; 4. metapelitos e metapsamitos com minerais indicadores de saturação em Al; 5. metapelitos e metapsamitos sem minerais formados pela saturação em $\mathrm{Al}$; 6. rochas com quartzo, sendo turmalina rica em $\mathrm{Fe}^{3+}$, associadas a rochas calciossilicáticas e metapelitos; 7. rochas metaultramáficas (baixo $\mathrm{Ca}$ ) e metassedimentares ricas em $\mathrm{Cr}$ e $\mathrm{V}$; 8. rochas carbonáticas metamorfizadas e metapiroxenitos. Campos 1 e 2 em (b) como em (a); 3. metapelitos, metapsamitos e rochas calciossilicáticas ricas em Ca; 4. metapelitos, metapsamitos pobres em Ca e rochas com quartzo e turmalina; 5 . rochas carbonáticas metamorfizadas; 6 . rochas metaultramáficas.

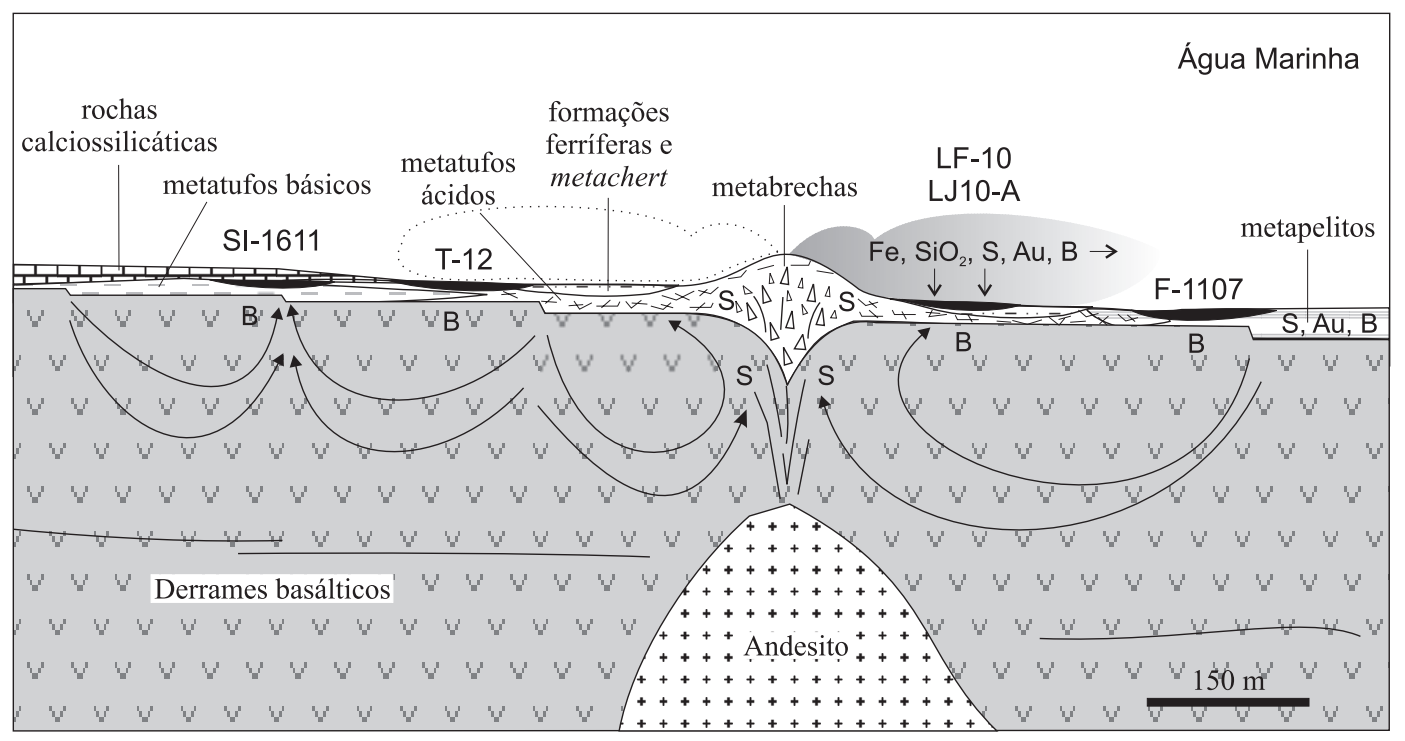

Figura 6. Representação esquemática de um sistema hidrotermal e localização dos turmalinitos em relação ao centro de atividade vulcano-exalativa (LF-10 e LJ10-A: proximais; T-12 e F-1107: intermediários, e SI-1611: distal). O calor gerado pela intrusão promove a circulação de fluidos pela pilha vulcano-sedimentar, mobilizando sílica e ferro (Fe) para a formação de metachert e formações ferríferas, boro (B), enxofre (S) e ouro (Au). 
Garda et al. (2002), utilizado para explicar os estágios de sulfetização e a mineralização de ouro ocorridos na área que abrange os pontos F-1107, LF-10, LJ-10-A e T-12, denominada Tapera Grande.

A geometria estratiforme dos turmalinitos de LF-10 e LJ-10-A, a sua associação com sedimentos químicos (formações ferríferas e metachert) e as estruturas sedimentares primárias localmente preservadas corroboram a origem exalativa e a proveniência do boro dos fluidos hidrotermais exalativos (conforme Plimer, 1988; Taylor e Slack, 1984). A turmalina que constitui essas rochas apresenta os teores mais elevados de $\mathrm{FeO}$ (em média 11,78\%), inferindo-se que tanto o turmalinito, como metachert e formações ferríferas associados correspondem às porções mais proximais em relação ao centro de atividade vulcano-exalativa. A turmalina também se destaca pelos teores médios de $\mathrm{Na}_{2} \mathrm{O}$ mais elevados $(2,07 \%)$, sendo que em algumas inclusões fluidas do metachert hospedeiro foram encontrados cristais de sal (Beljavskis, 2003).

Slack et al. (1993) apontam a dificuldade de conciliar, no modelo exclusivamente exalativo, o alto teor de alumínio encontrado nos turmalinitos com a baixa solubilidade do elemento e sua baixa concentração nos fluidos hidrotermais, salmouras e plumas de fundo oceânico. A remoção de alumínio das plumas próximas a fumarolas hidrotermais modernas é relativamente rápida, resultando em razões $\mathrm{Fe} / \mathrm{Al}$ altas nos fluidos hidrotermais submarinos. Assim, a turmalina que precipita a partir de fluidos exalativos consome uma quantidade maior de alumínio próximo às fumarolas, tornando os fluidos insaturados no elemento nas porções mais distais, não favorecendo a formação de turmalina diretamente de uma pluma hidrotermal ou salmoura por áreas muito extensas.

A substituição pode explicar a formação de turmalinitos em porções mais distais às fumarolas, proporcionando a geração de fontes de boro, alternativamente àquelas de origem exalativa. A circulação de água marinha quente em profundidade na crosta oceânica proporciona a lixiviação de boro e lítio dos sedimentos, rochas basálticas, vulcânicas félsicas e evaporitos. Com o resfriamento do fluido durante seu movimento ascendente, boro e lítio reprecipitam em níveis mais rasos, juntamente com a cristalização de esmectita e serpentina, fazendo com que o conteúdo de boro na crosta oceânica atinja 100 ppm (Shaw, 1996).

Para que haja precipitação de turmalina no assoalho oceânico, é necessário que os fluidos hidrotermais ricos em boro sejam ácidos e atinjam temperaturas superiores a $100^{\circ} \mathrm{C}$ (Slack et al., 1998). Nessas condições, os fluidos podem reagir seletivamente com sedimentos aluminosos ou tufos vulcânicos de composição intermediária a ácida, justificando os teores de $\mathrm{Si}, \mathrm{Al}, \mathrm{Fe}, \mathrm{Mg}, \mathrm{Na}$ e, até certo ponto, $\mathrm{Ca}$ encontrados na turmalina.

Os turmalinitos F-1107 e T-12 apresentam características sedimentares marcantes, como os clastos rip-up da amostra F-1107 (Figura 2b) e a composição química da amostra $\mathrm{T}-12$, muito semelhante à das rochas metassedimentares amostradas por sondagem rotativa em Tapera Grande (Beljavskis, 2003). A turmalina de F-1107 e T-12 apresenta os teores médios de $\mathrm{Al}_{2} \mathrm{O}_{3}$ mais elevados (ao redor de $32 \%$ ), o que condiz com a localização dessas amostras nos diagramas de Henry e Guidotti (1985), caracterizando sua associação com metapelitos e metapsamitos aluminosos. Nas porções mais intermediárias em relação ao centro de atividade vulcano-exalativa, começam a predominar na turmalina as características químicas das rochas encaixantes, pois são estas que fornecem $\mathrm{Al}$ para a turmalina com excesso do elemento. A turmalina da amostra F-1107 apresenta valores médios de $\mathrm{FeO}(10,84 \%)$ mais elevados que os obtidos para os dois grupos de turmalinas de T-12 (6,73\% e 9,29\%), contrariamente aos valores médios de $\mathrm{MgO}$ relativamente mais baixos $(4,40 \%$, ao passo que T-12 apresenta $6,67 \%$ e $5,21 \%)$. Os teores de $\mathrm{FeO}$ e $\mathrm{MgO}$ da turmalina da amostra T-12 também indicam sua posição mais intermediária em relação ao centro de atividade vulcano-exalativa (Figura 6), pois a composição da rocha hospedeira (metatufo básico) passa a predominar sobre as características do fluido hidrotermal.

A turmalina da amostra SI-1611 caracteriza esse turmalinito como distal em relação ao centro de atividade vulcano-exalativa, onde predominaram razões fluido/rocha mais baixas do que em F-1107 e T1-2. Porém, principalmente em função dos teores elevados de $\mathrm{F}$ encontrados na turmalina da amostra SI-1611 (em média 0,35\%), admite-se que fluidos magmáticos forneceram as quantidades de $\mathrm{B}$ necessárias para a formação desses turmalinitos. Os diagramas da Figura 5 (Henry e Guidotti, 1985) ressaltam a associação com rochas calciossilicáticas, metapelitos ricos em $\mathrm{Ca} e$ a presença de $\mathrm{Fe}^{3+}$ na turmalina, que compensa a insuficiência de Al. Sua posição mais distal é, portanto, marcada pelos baixos teores de $\mathrm{Al}_{2} \mathrm{O}_{3}$ e pelos teores elevados de $\mathrm{MgO}$ e $\mathrm{CaO}$, indicando baixas razões fluido/rocha.

\section{APLICAÇÕES NA GEOLOGIA ECONÔMICA}

Slack (1996) destaca que a maioria dos eventos geradores de turmalinitos não produz concentrações econômicas de metais. Entretanto, os turmalinitos podem indicar a instalação de um sistema geotermal durante a deposição da seqüência vulcano-sedimentar, fazendo com que sua presença implique maior potencialidade para a formação de depósitos exalativos de $\mathrm{Pb}-\mathrm{Zn}, \mathrm{Cu}-\mathrm{Zn}, \mathrm{Cu}-\mathrm{Co}$, W, e $\mathrm{Au}$ (Plimer, 1980, 1988; Slack, 1982; Taylor e Slack, 1984). Alguns exemplos de mineralizações de sulfetos maciços e ouro associados a sistemas hidrotermais desse tipo estão relacionados nas Tabelas 2 e 3. 
Segundo Plimer (1988), os turmalinitos são raramente encontrados no interior das zonas de alteração hidrotermal da base dos depósitos ou do minério de origem exalativa, sugerindo que a precipitação da turmalina ocorre a temperaturas mais baixas, $\mathrm{pH}$ mais elevado e sob condições mais oxidantes do que aquelas dos sulfetos. Slack et al. (1998) mostram que, no âmbito dos black smokers, para a formação de depósitos de sulfetos maciços de $\mathrm{Fe}-\mathrm{Zn}-\mathrm{Pb}$, são necessárias temperaturas mais elevadas e fluidos hipersalinos.

Ethier e Campbell (1977), por sua vez, sugerem que a composição da turmalina pode ser utilizada como guia na prospecção mineral, exemplificando com a turmalina rica em $\mathrm{Mg}$ encontrada junto aos depósitos de $\mathrm{Pb}-\mathrm{Zn}-\mathrm{Ag}$ de
Sullivan. Slack (1982) e Taylor e Slack (1984) concordam com Ethier e Campbell (1977), sendo que Slack (1996) estende tal proposição para os turmalinitos magnesianos, não importando a origem do enriquecimento em $\mathrm{Mg}$. Isto é válido para composições de turmalina influenciadas por fluidos hidrotermais cujo componente dominante é a água marinha ou de origem evaporítica, ou por reações metamórficas envolvendo sulfeto e/ou silicato, tanto em terrenos metassedimentares clásticos ou metavulcânicos. Entretanto, Henry e Guidotti (1985) observam que, em terrenos carbonáticos e evaporíticos, a ocorrência de turmalina rica em Mg não implica a presença de mineralizações de sulfetos, ouro ou scheelita.

Tabela 2. Variação na composição química das turmalinas associadas a depósitos de metais-base.

\begin{tabular}{|c|c|c|c|c|c|}
\hline Localização & Ocorrência da turmalina & Mineralização & $\begin{array}{c}\mathrm{FeO} /(\mathrm{FeO}+\mathrm{MgO}) \\
\% \text { em peso }\end{array}$ & $\begin{array}{c}\mathrm{NaO} /(\mathrm{NaO}+\mathrm{CaO}) \\
\% \text { em peso }\end{array}$ & Referência \\
\hline $\begin{array}{c}\text { Sullivan } \\
\text { (British Columbia, Canadá) }\end{array}$ & Turmalinito em rocha metassedimentar & $\mathrm{Pb}, \mathrm{Zn}, \mathrm{Ag}$ & $\begin{array}{l}\mathrm{I}=0,23-0,32 \\
\mathrm{II}=0,45-0,67 \\
\mathrm{II}=0,82-0,91\end{array}$ & $\begin{array}{l}0,33-0,90 \\
0,62-0,73 \\
0,83-0,94 \\
\end{array}$ & $\begin{array}{c}\text { Ethier e Campbell (1977) } \\
\text { Beaty et al. (1987) }\end{array}$ \\
\hline $\begin{array}{c}\text { Kidd Creek } \\
\text { (Timmins-Ontario, Canadá) }\end{array}$ & Turmalinito & $\mathrm{Cu}, \mathrm{Pb}, \mathrm{Zn}$ & $0,53-0,77$ & $0,78-0,97$ & Slack e Coad (1989) \\
\hline $\begin{array}{l}\text { Trestle Creek } \\
\text { (Idaho, EUA) }\end{array}$ & Rocha metassedimentar & $\mathrm{Pb}, \mathrm{Zn}, \mathrm{Ag}$ & $0,46-0,64$ & & Beaty et al. (1987) \\
\hline $\begin{array}{c}\text { Ore Knob } \\
\text { (Orógeno Apalachiano- } \\
\text { Caledoniano, EUA) } \\
\end{array}$ & Rocha metassedimentar & $\mathrm{Cu}$ & $0,36-0,44$ & $0,69-0,76$ & Taylor e Slack (1984) \\
\hline $\begin{array}{c}\text { Cuyuna Iron Range } \\
\text { (Minnesota, EUA) }\end{array}$ & Turmalinito & $\begin{array}{c}\mathrm{Mn} \\
\text { (potencial para } \\
\text { Cu-Pb-Zn-Ba) } \\
\end{array}$ & $I V=0,57-0,81$ & $0,31-1,00$ & Cleland et al. (1996) \\
\hline $\begin{array}{l}\text { Broken Hill } \\
\text { (Austrália) }\end{array}$ & $\begin{array}{c}\text { Turmalinito } \\
\text { Turmalinito } \\
\text { Rocha metassedimentar } \\
\end{array}$ & $\begin{array}{l}\mathrm{Pb}, \mathrm{Zn}, \mathrm{Ag} \\
\mathrm{Pb}, \mathrm{Zn}, \mathrm{Ag} \\
(\mathrm{W})\end{array}$ & $\begin{array}{l}0,81 \\
0,81 \\
0,76 \\
\end{array}$ & $\begin{array}{l}0,84 \\
0,79 \\
0,78 \\
\end{array}$ & $\begin{array}{c}\text { Plimer (1988), } \\
\text { Slack et al. (1993) }\end{array}$ \\
\hline $\begin{array}{c}\text { Rum Jungle } \\
\text { (Austrália) }\end{array}$ & Turmalinito & $\mathrm{Cu}, \mathrm{Pb}, \mathrm{Zn}$ e U & $0,21-0,87$ & $0,64-0,91$ & Bone (1988) \\
\hline $\begin{array}{l}\text { Aggeneys e Gamsberg } \\
\text { (Bushmanland Central, } \\
\text { África do Sul) }\end{array}$ & $\begin{array}{c}\text { Turmalinito } \\
\text { rocha metassedimentar }\end{array}$ & $\mathrm{Zn}, \mathrm{Pb}, \mathrm{Cu}$ & $\begin{array}{c}0,33-0,57 \\
0,68\end{array}$ & $\begin{array}{c}0,64-0,70 \\
0,53\end{array}$ & Willner (1992) \\
\hline $\begin{array}{l}\text { Guangxi } \\
\text { (China) }\end{array}$ & $\begin{array}{c}\text { Turmalinito em rocha metassedimentar } \\
\text { Turmalinito tipo lode } \\
\text { Biotita granito } \\
\text { Greisen }\end{array}$ & $\begin{array}{c}\mathrm{Sn} \\
(\mathrm{Cu}),(\mathrm{Pb}),(\mathrm{Zn})\end{array}$ & $\begin{array}{c}0,46-0,53 \\
0,77-0,94 \\
0,88-0,94 \\
0,92\end{array}$ & $\begin{array}{l}0,50-0,68 \\
0,38-0,45 \\
0,83-0,94 \\
0,90-0,93\end{array}$ & Mao (1995) \\
\hline $\begin{array}{c}\text { Isua } \\
\text { (Groenlândia) }\end{array}$ & $\begin{array}{l}\text { Turmalinito em rocha vulcanoclástica félsica } \\
\text { Turmalinito em rocha vulcanoclástica máfica }\end{array}$ & (W) & $\begin{array}{c}0,63 \\
0,30-0,62\end{array}$ & $\begin{array}{c}0,73 \\
0,73-0,88\end{array}$ & Appel (1995) \\
\hline
\end{tabular}

Tabela 3. Variação na composição química das turmalinas associadas a depósitos de ouro.

\begin{tabular}{|c|c|c|c|c|c|}
\hline Localização & Ocorrência da turmalina & Mineralização & $\begin{array}{l}\mathrm{FeO} /(\mathrm{FeO}+\mathrm{MgO}) \\
\% \text { em peso }\end{array}$ & $\begin{array}{c}\mathrm{NaO} /(\mathrm{NaO}+\mathrm{CaO}) \\
\% \text { em peso }\end{array}$ & Referência \\
\hline $\begin{array}{c}\text { Buffalo Ankerite e Beaumount } \\
\text { (Timmins-Porcupine, Ontario, Canadá) }\end{array}$ & $\begin{array}{l}\text { Dravita rica em } \mathrm{Cr} \text { em } \\
\text { veios de quartzo }\end{array}$ & $\mathrm{Au}$ & $\begin{array}{l}0,22-0,29 \\
0,29-0,40\end{array}$ & $\begin{array}{l}0,98-1,00 \\
0,99-1,00\end{array}$ & $\begin{array}{l}\text { King e Kerrich } \\
\text { (1989) }\end{array}$ \\
\hline $\begin{array}{l}\text { Bin Yauri } \\
\text { (Nigéria) }\end{array}$ & $\begin{array}{c}\text { Turmalinito } \\
\text { Veios } \\
\text { Hornfels } \\
\end{array}$ & $\mathrm{Au}$ & $\begin{array}{c}V=0,63 \\
V I=0,54-0,62 \\
0,55-0,60\end{array}$ & $\begin{array}{l}0,87-0,91 \\
0,87-0,95 \\
0,81-0,84 \\
\end{array}$ & $\begin{array}{r}\text { Garba } \\
(1996)\end{array}$ \\
\hline $\begin{array}{c}\text { Guibaré e Fété Kolé } \\
\text { (Burkina Faso, Birmânia) }\end{array}$ & Veios de quartzo & $\mathrm{Au}$ & $\begin{array}{c}\mathrm{VI}=0,53-0,66 \\
0,61-0,75\end{array}$ & $\begin{array}{l}0,93-0,96 \\
0,72-0,92 \\
\end{array}$ & $\begin{array}{c}\text { Béziat et al. } \\
(1999)\end{array}$ \\
\hline $\begin{array}{l}\text { Cosmopolitan, Howley e Golden Dyke Dome } \\
\text { (Austrália) }\end{array}$ & $\begin{array}{c}\text { Turmalinito em seqüência } \\
\text { vulcano-sedimentar }\end{array}$ & $\mathrm{Au}$ & $\begin{array}{c}0,45 \\
0,27-0,50 \\
\end{array}$ & $\begin{array}{c}0,66 \\
0,30-0,85\end{array}$ & $\begin{array}{l}\text { Plimer } \\
(1986) \\
\end{array}$ \\
\hline $\begin{array}{l}\text { Kirwans Hill e Doctor Hill } \\
\text { (Nova Zelândia) }\end{array}$ & $\begin{array}{c}\text { Veios de quartzo } \\
\text { Granito }\end{array}$ & $\begin{array}{l}\text { Sn, W, Au } \\
\text { Sn, W }\end{array}$ & $\begin{array}{l}0,47-0,60 \\
0,67-0,81 \\
\end{array}$ & $\begin{array}{l}0,57-0,97 \\
0,72-0,92\end{array}$ & $\begin{array}{c}\text { Pirajno e Smithies } \\
(1992)\end{array}$ \\
\hline $\begin{array}{l}\text { Salikvan - Artvin } \\
\text { (Turquia) }\end{array}$ & $\begin{array}{c}\text { Veios de quartzo } \\
\text { Tonalito pórfiro } \\
\text { Rochas com turmalina }\end{array}$ & Cu-Mo & $\begin{array}{l}0,43-0,66 \\
0,60-0,67 \\
0,43-0,56\end{array}$ & $\begin{array}{l}0,28-0,55 \\
0,39-0,51 \\
0,28-0,55\end{array}$ & $\begin{array}{c}\text { Yavuz et al. } \\
(1999)\end{array}$ \\
\hline
\end{tabular}


Beaty et al. (1987), Hellingwerf et al. (1994), Slack (1996) e Griffin et al. (1996) reforçam a existência da correlação entre turmalina rica em $\mathrm{Mg}$ e depósitos de sulfetos, o que pode constituir um guia em trabalhos de exploração mineral. Griffin et al. (1996) destacam que certos elementos traços presentes em turmalina $(\mathrm{Cu}, \mathrm{Pb}, \mathrm{Zn}, \mathrm{Sn}, \mathrm{Ba}, \mathrm{Sr}$ e Ga) são também diagnósticos do tipo de depósito de sulfeto maciço.

Mineralizações de ouro relacionadas a turmalinitos são citadas por Plimer (1986) em Northern Territory (Austrália) e por MacArdle et al. (1989) nos Caledonides do Sudeste da Irlanda. Garba (1996) propõe, em seu estudo sobre turmalinização associada a mineralizações auríferas do tipo lode em Bin Yauri (Nigéria), que a turmalina é um indicador útil para o entendimento das condições geoquímicas e físicoquímicas dos fluidos hidrotermais auríferos. King (1988) mostra que a turmalina associada aos depósitos de ouro do tipo lode da Província Superior (Canadá) caracteriza-se por teores de $\mathrm{Fe}$ mais elevados que os de $\mathrm{Mg}$, baixos teores de $\mathrm{Li}$, e valores de $\delta^{18} \mathrm{O}$ entre $+8,8 \mathrm{e}+12,1 \%$ p para turmalina e entre $+12 \mathrm{e}+14 \%$ o para o quartzo associado.

$\mathrm{Na}$ Figura 7 estão representadas as razões $\mathrm{Na}_{2} \mathrm{O} /\left(\mathrm{Na}_{2} \mathrm{O}\right.$ $+\mathrm{CaO})$ e $\mathrm{FeO} /(\mathrm{FeO}+\mathrm{MgO})$ para a turmalina de turmalinitos da Formação Morro da Pedra Preta e de algumas áreas mineralizadas, assinaladas com algarismos romanos nas Tabelas 2 e 3. Relativamente aos sulfetos de metais-base, a turmalina das amostras F-1107, LF-10, LJ10-A e T-12 plota fora dos campos I (turmalina de granulação grossa, com $\mathrm{MgO}=10,11 \%$ ), II (schorlita-dravita disseminada nas rochas metassedimentares da Formação Aldridge) e III (schorlita do stock de Hellroaring), que representam a mineralização de $\mathrm{Pb}-\mathrm{Zn}-\mathrm{Ag}$ de Sullivan.

A turmalina da amostra SI-1611, cujo conteúdo de MgO mais se aproxima ao da turmalina magnesiana de Sullivan, distingue-se desta pelos baixos teores de $\mathrm{Na}_{2} \mathrm{O}$ (média de $2,07 \%$ ) e altos teores de $\mathrm{CaO}$ (média de 3,37\%), que resultam nos valores mais baixos $(0,22)$ da razão $\mathrm{Na}_{2} \mathrm{O} /\left(\mathrm{Na}_{2} \mathrm{O}+\mathrm{CaO}\right)$.

Em relação ao ouro, a composição da turmalina com $\mathrm{FeO}<8,3 \%$ da amostra T-12 situa-se nas proximidades do campo VI (Guibaré, Fété Kolé e Bin Yauri), enquanto as demais distribuem-se junto ao campo V (Bin Yauri). As composições da turmalina associada a esses depósitos em veios de quartzo e as da turmalina das amostras F-1107, LF-10, LJ10-A e T-12 são também semelhantes às da turmalina associada aos depósitos de $\mathrm{Fe}-\mathrm{Mn}$ de Cuyuna North Range (campo IV), cuja gênese é tida como sedimentar-exalativa e não apenas sedimentar, pela presença de turmalinito (Cleland et al., 1996).

No caso da Formação Morro da Pedra Preta, a relação entre as formações ferríferas, metachert e turmalinitos é mais consistente com mineralizações de ouro, do que propriamente de sulfetos maciços, tal como observado nos corpos

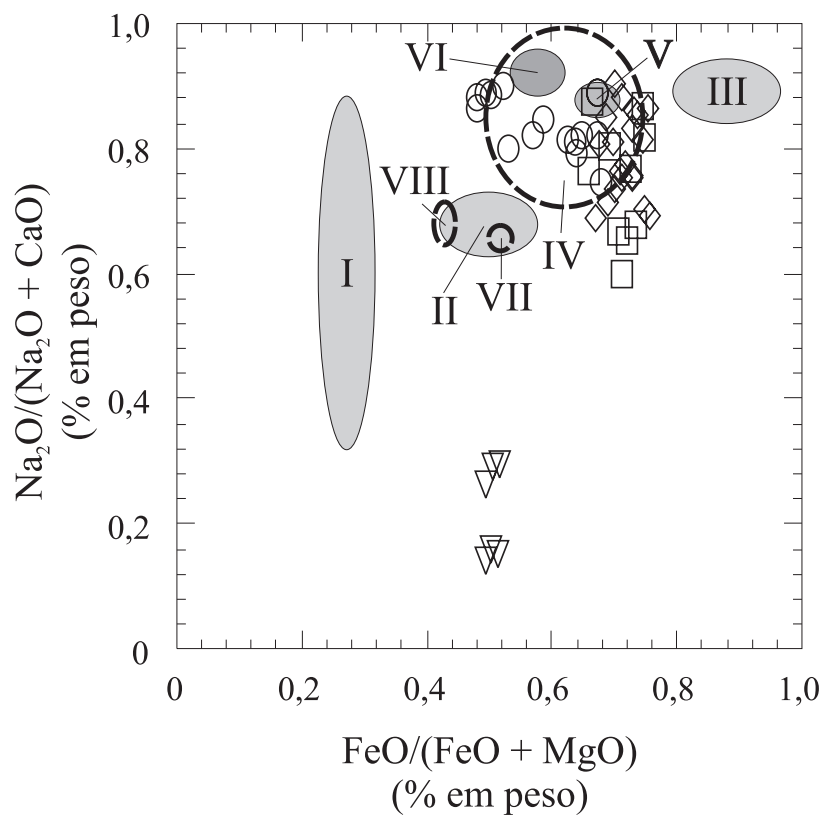

SI-1611 $\bigcirc$ T12 $\diamond$ LF-10 e LJ10-A $\square$ F-1107

Figura 7. Diagrama $\mathrm{Na}_{2} \mathrm{O} /\left(\mathrm{Na}_{2} \mathrm{O}+\mathrm{CaO}\right)$ vs. $\mathrm{FeO} /(\mathrm{FeO}+\mathrm{MgO})$ destacando os campos composicionais da turmalina dos turmalinitos de Sullivan (I - junto à mineralização de $\mathrm{Pb}-\mathrm{Zn}-\mathrm{Ag}$, II - metassedimentos da Formação Aldridge e III - Hellroaring Creek Stock); IV - North Range-Cuyuna (Fe-Mn); V - Bin Yauri (Au); VI - Bin Yauri (Au), Guibaré e Féte Kolé (Au); VII - Cosmopolitan Howley Mine (Au); e VIII - Golden Dyke Dome (Au), conforme assinalado com algarismos romanos nas Tabelas 2 e 3 .

LF-10, LJ10-A e T-12. De fato, com base na composição química da turmalina, parece não haver potencial para ocorrências de depósitos de metais-base, uma vez que a turmalina não é tipicamente magnesiana e formou-se em ambientes onde predominam baixas razões fluido/rocha.

\section{CONCLUSÕES}

As composições da turmalina das amostras de turmalinito LF-10, LJ10-A, T-12 e F-1107 (Tapera Grande) são intermediárias à série schorlita-dravita, enquanto as de SI-1611 (a NW de Tapera Grande) tendem para a composição da uvita, sendo também as mais ricas em flúor.

Os turmalinitos de Tapera Grande associam-se com rochas metavulcânicas, formações ferríferas, metacherts e rochas metassedimentares. Formaram-se em ambiente marinho profundo, pelos processos de substituição e exalativo, 
tendo este último atuado com maior intensidade na formação de LF-10 e LJ10-A. Esses turmalinitos formaram-se em zonas mais proximais ao centro de atividade vulcanoexalativa, ao passo que F-1107 e T-12 em porções mais intermediárias, onde as razões fluido/rocha eram mais baixas relativamente às zonas mais proximais. As fontes de Al e B para a formação desses turmalinitos foram principalmente os metassedimentos e metatufos básicos hospedeiros.

A formação dos turmalinitos de Tapera Grande está relacionada aos estágios I e II de sulfetização de Garda et al. (2002), podendo ser contemporânea ao estágio I (sinsedimentar) e anterior ao estágio II (de caráter pervasivo). A circulação de fluidos (água marinha) pela pilha vulcanosedimentar, impulsionada pelo calor oriundo de corpos dacíticos e andesíticos subjacentes, promoveu a recristalização de chert, mobilização de ouro e boro e deposição dos sulfetos dos estágios I e II.

O turmalinito SI-1611 formou-se distalmente em relação ao centro de atividade vulcano-exalativa. A turmalina desse turmalinito contém flúor, elemento que pode ser utilizado, de acordo Willner (1992), como traçador da origem das soluções hidrotermais, uma vez que essas podem estar associadas a intrusões ígneas, ricas no elemento (por exemplo, metarriolitos ricos em flúor, ocorrendo em profundidade).

A composição química da turmalina dos turmalinitos estudados indica maior potencialidade da Formação Morro da Pedra Preta para a ocorrência de depósitos de ouro. Eventos posteriores, relacionados à geração de veios de quartzo (metamorfismo, intrusão de corpos graníticos neoproterozóicos e cisalhamento), contribuíram para a remobilização do ouro e dos sulfetos.

Em outras unidades metassedimentares e metavulcanosedimentares meso- e neoproterozóicas do Cinturão Ribeira, além das ocorrências de metais preciosos, foram encontrados também depósitos de sulfetos de metais-base. A caracterização dos turmalinitos associados a esses depósitos utilizando a composição química da turmalina pode auxiliar no reconhecimento dos prováveis sistemas hidrotermais sina pós-deposicionais que geraram os depósitos. Desta forma, os turmalinitos podem vir a constituir importante ferramenta nos trabalhos de prospecção mineral. Particularmente no Cinturão Ribeira, podem contribuir para a definição de áreas com maior potencial para a ocorrência de mineralizações de $\mathrm{Cu}-\mathrm{Pb}-\mathrm{Zn}$ ou de $\mathrm{Au}-\mathrm{Ag}$.

\section{AGRADECIMENTOS}

Os autores agradecem à FAPESP pelo apoio financeiro concedido via processo 98/05526-09 e aos relatores, que por meio das sugestões e críticas, contribuíram para a melhoria substancial do texto.

\section{REFERÊNCIAS BIBLIOGRÁFICAS}

ALMEIDA, F. F. M. et al. A. Mapa geológico do Estado de São Paulo, escala 1:500.000 - v. 1: nota explicativa. São Paulo: IPT, 1981.126 p. (IPT, Monografias).

APPEL, P. W. U. Tourmalinites in the 3800 Ma old Isua supracrustal belt, West Greenland. Precambrian Research, v. 72, p. 227-234, 1995.

BEATY, D. W.; HAHN, G. A.; THRELKED, W. E. Field isotopic and studies of tourmaline-bearing rocks in the BeltPurcell Supergroup: genetic constraints and exploration significance for Sullivan type ore deposits. Canadian Journal of Earth Sciences, v. 25, p. 392-402, 1987.

BELJAVSKIS, P. Caracterização das mineralizações e os ambientes deposicionais dos sulfetos, turmalinas e ouro no contexto da Formação Morro da Pedra Preta, Grupo Serra do Itaberaba - SP. 2003.148 p. Tese (Doutorado) - Instituto de Geociências, Universidade de São Paulo, São Paulo.

BÉZIAT, D. et al. The Guibaré and Fété Kolé gold-bearing tourmaline-quartz veins in the Birimian greenstone belts of Burkina Faso. Canadian Mineralogist, v. 37, p. 575-591, 1999.

BONE, Y. The geological setting of tourmaline at Rum Jungle, N.T.; Australia. Genetic and economic implications. Mineralium Deposita, v. 23, p. 34-41, 1988.

CLELAND, J. M.; MOREY, G. B.; MACSWIGGEN, P. L. Significance of tourmaline-rich rocks in the North Range Group of the Cuyuna Iron Range, east-central Minnesota. Economic Geology, v. 91, p. 1282-1291, 1996.

ETHIER, V. G.; CAMPBELL, F. A. Tourmaline concentrations in Proterozoic sediments of the southern Cordillera of Canada and their economic significance. Canadian Journal of Earth Sciences, v. 14, p. 2348-2363, 1977.

FLEISCHER, R.; ROUTHIER, P. The “consanguineous" origin of the tourmaline-bearing gold deposit: Passagem de Mariana, Brazil. Economic Geology, v. 68, p. 11-22, 1973.

GARBA, I. Tourmalinization related to Late Proterozoic-Early Paleozoic lode gold mineralization in the Bin Yauri area, Nigeria. Mineralium Deposita, v. 31, p. 201-209, 1996.

GARDA, G. M. et al. Geochemistry of tourmalines associated with iron formation and quartz veins of the Morro da Pedra Preta Formation, Serra do Itaberaba Group (São Paulo, Brazil). Anais daAcademia Brasileira de Ciências, v. 75, p. 209-234, 2003. 
GARDA, G. M. et al. Sulfur stable signature of the Morro da Pedra Preta Formation, Serra do Itaberaba Group, Sao Paulo State, Brazil. Geochimica Brasiliensis, v. 16, p. 79-97, 2002.

GRIFFIN, W. L. et al. Trace elements from massive sulfide deposits and tourmalinites: geochemical controls and exploration applications. Economic Geology, v. 91, p. 657-675, 1996.

HAWTHORNE, F. C.; HENRY, D. J. Classification of the minerals of the tourmaline group. European Journal of Mineralogy, v. 11, p.201-215, 1999.

HELLINGWERF, R. H. et al. Tourmaline in central Swedish ore district. Mineralium Deposita, v. 29, p. 189-205, 1994.

HENRY, D. J.; GUIDOTTI, C. V. Tourmaline as a petrogenetic indicator mineral: an example from the staurolite-grade metapelites of NW Maine. American Mineralogist, v. 70, p. 1-15, 1985.

JIANG, S.Y. et al. Paragenesis and chemistry of multistage Tourmaline Formation in the Sullivan $\mathrm{Pb}-\mathrm{Zn}-\mathrm{Ag}$ deposit, British Columbia. Economic Geology, v. 93, p. 47-67, 1998.

JULIANI, C. Geologia, petrogênese e aspectos metalogenéticos dos grupos Serra do Itaberaba e São Roque na região das serras do Itaberaba e da Pedra Branca, NE da cidade de São Paulo, SP. 1993. 2 v. Tese (Doutorado) - Instituto de Geociências, Universidade de São Paulo, São Paulo.

JULIANI, C.; BELJAVSKIS, P. Revisão da litoestratigrafia da faixa São Roque/Serra do Itaberaba (SP). Revista do Instituto Geológico, v. 16, p. 33-58, 1995.

JULIANI, C.; BELJAVSKIS, P.; SCHORSCHER, J. H. D. Petrogênese do vulcanismo e aspectos metalogenéticos associados: Grupo Serra do Itaberaba na região do Grupo São Roque - SP. In: CONGRESSO BRASILEIRO DE GEOLOGIA, 34., 1986, Goiânia. Anais... Goiânia: SBG, 1986. v. 2,p. 730-745.

JULIANI, C.; PÉREZ-AGUILAR, A.; MARTIN, M. A. B. Geotermobarometria e evolução metamórfica P-T-d do Grupo Serra do Itaberaba (SP). Anais da Academia Brasileira de Ciências, v. 69, p. 441-442, 1997.

JULIANI, C. et al. The Mesoproterozoic volcano-sedimentary Serra do Itaberaba Group of the central Ribeira Belt, São Paulo State, Brazil: implication for the age of overlying São Roque Group. Revista Brasileira de Geociências, v. 30, p. 82-86, 2000 .
KING, R. J. Minerals explained 28: the tourmaline group Part 1. Geology Today, v. 16, p. 35-37, 2000.

KING, R. W. Geochemical characteristics of tourmaline from Superior Province Archean lode gold deposits: implications for source regions and processes. Geological Society of Australia Abstract Series, n. 22, p. 445-447, 1988. Presented in Bicentennial Gold 88.

KING, R. W.; KERRICH, R. Chromian dravite associated with ultramafic-rock-hosted Archean lode gold deposits, TimminsPorcupine District, Ontario. Canadian Mineralogist, v. 27, p. 419-426, 1989.

MAO, J. W. Tourmalinite from northern Guangxi, China. Mineralium Deposita, v. 30, p. 235-245, 1995.

MacARDLE, P. et al. Tourmalinite as a potential host rock for gold Caledonides of southeast Ireland. Mineralium Deposita, v. 24, p. 154-159, 1989.

PIRAJNO, F.; SMITHIES, R. H. The FeO/(FeO + MgO) ratio of tourmaline: a useful indicator of spatial variations in granite-related hydrothermal mineral deposits. Journal of Geochemical Exploration, v. 42, p. 371-381, 1992.

PLIMER, I. R. Exhalative Sn and W deposits associated with mafic volcanism as precursors to $\mathrm{Sn}$ and $\mathrm{W}$ deposits with granites. Mineralium Deposita, v. 15, p. 275-289, 1980.

PLIMER, I. R. Tourmalinites from the Golden Dyke Dome, Northern Australia. Mineralium Deposita, v. 21, p. 263-270, 1986.

PLIMER, I. R. Tourmalinites associated with Proterozoic submarine exhalative ores. In: FRIEDERICH, G. H.; HERZIG, P. M. (Ed.). Base metal sulfide deposits in sedimentary and volcanic environments. Berlin: Springer-Verlag, 1988. p. 255-283.

SHAW, D. M. Similarities and contrasts in lunar and terrestrial boron geochemistry. In: GREW, E. S.; ANOVITZ, L. M. (Ed.). Boron: mineralogy, petrology and geochemistry. Washington: The Mineralogical Society of America, 1996. p. 745-769. (Reviews in Mineralogy, 33).

SLACK, J. F. Tourmaline in Appalachian-Caledonian massive sulphide deposits and its exploration significance. Institution of Mining and Metallurgy Transactions, v. 91, p. B81-B89, 1982.

SLACK, J. F. Tourmaline associations with hydrothermal 
ore deposits. In: GREW, E. S.; ANOVITZ, L. M. (Ed.). Boron: mineralogy, petrology and geochemistry. Washington: The Mineralogical Society of America, 1996. p. 559-643. (Reviews in Mineralogy, 33).

SLACK, J. F.; COAD, R. P. Multiple hydrothermal and metamorphic events in Kidd Creek volcanogenic massive sulphide deposit, Timmins, Ontario: evidence from tourmalines and chlorites. Canadian Journal of Earth Sciences, v. 26, p. 694-715, 1989.

SLACK, J. F. et al. Stratiform tourmalinites in metamorphic terranes and their geologic significance. Geology, v. 12, p. 713-716, 1984.

SLACK, J. F. et al. Origin and significance of tourmaline-rich rocks in the Broken Hill district, Australia. Economic Geology, v. 88, p. 505-541, 1993.

SLACK, J. F. et al. Boron-rich mud volcanoes of the Black Sea region: modern analogues to ancient sea-floor tourmalinites associated with Sullivan-type $\mathrm{Pb}-\mathrm{Zn}$ deposits? Geology, v. 26, p. 439-442, 1998.

TAYLOR, R. P.; SLACK, J. F. Tourmalines from AppalachianCaledonian massive sulfide deposits: textural, chemical, and isotopic relationships. Economic Geology, v. 79, p. 1703-1726, 1984.

WILLNER, A. P. Tourmalinites from the stratiform peraluminous metamorphic suite of the Central Namaqua Mobile Belt South Africa. Mineralium Deposita, v. 27, p. 304-313, 1992.

YAVUZ, F. TOURMAL: Software package for tourmaline, tourmaline-rich rocks and related ore deposits. Computers and Geosciences, v. 23, p. 947-959, 1997.

YAVUZ, F. et al. Tourmaline compositions from the Salikvan porphyry $\mathrm{Cu}-\mathrm{Mo}$ deposit and vicinity, northeastern Turkey. The Canadian Mineralogist, v. 37, p. 1007-1023, 1999. 